\title{
Pushing Typists Back on the Learning Curve: Revealing Chunking in Skilled Typewriting
}

\author{
Motonori Yamaguchi and Gordon D. Logan \\ Vanderbilt University
}

\begin{abstract}
Theories of skilled performance propose that highly trained skills involve hierarchically structured control processes. The present study examined and demonstrated hierarchical control at several levels of processing in skilled typewriting. In the first two experiments, we scrambled the order of letters in words to prevent skilled typists from chunking letters, and compared typing words and scrambled words. Experiment 1 manipulated stimulus quality to reveal chunking in perception, and Experiment 2 manipulated concurrent memory load to reveal chunking in short-term memory (STM). Both experiments manipulated the number of letters in words and nonwords to reveal chunking in motor planning. In the next two experiments, we degraded typing skill by altering the usual haptic feedback by using a laser-projection keyboard, so that typists had to monitor keystrokes. Neither the number of motor chunks (Experiment 3) nor the number of STM items (Experiment 4) was influenced by the manipulation. The results indicate that the utilization of hierarchical control depends on whether the input allows chunking but not on whether the output is generated automatically. We consider the role of automaticity in hierarchical control of skilled performance.
\end{abstract}

Keywords: hierarchical control, skilled performance, motor chunk, automatic processes, unit of processing

Complex skills consist of multiple cognitive and perceptualmotor components. Skilled performers are able to utilize these component processes in concert to optimize performance. To implement multiple components in a rapid succession, skilled performance requires hierarchically organized control processes (Lashley, 1951). Although the notion of hierarchical control has appeared in psychological literature many times (e.g., Abrahamse, Ruitenberg, de Kleine, \& Verwey, 2013; Bryan \& Harter, 1899; Cooper \& Shallice, 2000; Leonard \& Newell, 1964; MacKay, 1982; Miller, Galanter, \& Pribram, 1960; Rhodes, Bullock, Verwey, Averbeck, \& Page, 2004; Verwey, 2001), it remains controversial (e.g., Botvinick \& Plaut, 2004; Cooper \& Shallice, 2006; Elman, 1990). Studies of typewriting are particularly suited to address the hierarchical nature of skilled performance (Fendrick, 1937; Logan \& Crump, 2011; Salthouse, 1986; Shaffer, 1975a; Yamaguchi, Crump, \& Logan, 2013). Thus, the present study investigated hierarchical control in the context of typewriting.

Hierarchical control involves higher-level processes that determine the functioning of lower-level processes (Lashley, 1951; Logan \& Crump, 2011; Miller et al., 1960). There are four defining properties of hierarchical control (Logan \& Crump, 2011): First,

This article was published Online First July 22, 2013.

Motonori Yamaguchi, Gordon D. Logan, Department of Psychology, Vanderbilt University.

This research was supported by grant numbers BCS 0957074 and BCS 1257272 from the National Science Foundation. We thank Vanessa Li for her help collecting data.

Correspondence concerning this article should be addressed to Motonori Yamaguchi, Department of Psychology, Vanderbilt University, Nashville, TN 37221. E-mail: motonori.yamaguchi@vanderbilt.edu different levels of hierarchical control are sensitive to different aspects of the environment (selective influence). Second, different levels of hierarchical control operate on different units of processing (chunking). Third, different levels of hierarchical control divide intellectual labor and operate autonomously (encapsulation). Finally, different levels of hierarchical control rely on different sources of feedback to their actions (distinct feedback sources). The present study focused on chunking in skilled typewriting. We provide evidence indicating chunking at several levels of processing and examine conditions under which hierarchical control is utilized in skilled typewriting.

\section{Hierarchical Control of Skilled Performance}

Lashley (1951) provided seminal analyses of skilled performance, in which he pointed out that the intervals between successive actions are too short for the sensory consequences of one action to trigger the next in a serial fashion (Keele \& Posner, 1968). To achieve such rapid expression of skill, a set of elementary actions must be processed as a single unit, or a "chunk" (Miller, 1956). Chunking benefits performance by enabling parallel processing of component actions and reducing cognitive load in maintaining action plans, which allows skilled performers to concentrate on higher-level action goals (e.g., Newell \& Rosenbloom, 1981; Vallacher \& Wegner, 1987).

Typewriting provides a good example of hierarchical control. Typewriting involves controlling complex sequences of keystrokes while concentrating on copying or composing complex sentences. Yet, skilled typists type very quickly compared with novices (Butsch, 1932; Fendrick, 1937; Salthouse, 1984). The differences between skilled typists and novices stem from the way typing is controlled (Bryan \& Harter, 1899; Lashley, 1951; Logan \& 
Crump, 2011). Novice typists control typing with a "hunt-and-peck" method, reading each letter, finding the corresponding key on the keyboard, moving a finger to the key, and pressing it. Hunt-and-peck typing imposes serial processing of letters and keystrokes. By contrast, skilled typists control typing with a "touch-typing" method, reading a word, activating its constituent keystrokes in parallel, and executing them serially but temporally overlapping (e.g., Rumelhart \& Norman, 1982). In contrast to hunt-and-peck typing, touch-typing requires letters or keystrokes to be processed in parallel. This parallel processing depends on hierarchical control, in which several letters and keystrokes are processed as a single unit, or a chunk (Lashley, 1951; Logan \& Crump, 2011).

Logan and Crump (2011) distinguished between two levels of hierarchical control in skilled typing, implemented as an outer loop and an inner loop (see Figure 1a). The outer loop is a higher-level control process that comprehends language, decomposes sentences into individual words, and submits the words to the inner loop one at a time. The inner loop is a lower-level control process that receives words from the outer loop, activates their keystrokes in parallel, and executes them in the correct order. The unit of processing in the outer loop is a single word, and the unit of processing in the inner loop is a single letter or keystroke (see Figure 1b). The two loops rely on different sources of feedback (Logan \& Crump, 2010). The outer loop monitors visual feedback from the display, detecting errors in the words typed on the display; the inner loop monitors haptic feedback from the keys (e.g., the feel of the edges and depressions in the keys, and the resistance of the keys when they are pressed) and tracks finger positions on the keyboard (e.g., aligning the fingers with the keyboard and directing the fingers to the keys). This separation of feedback sources allows the two loops to operate autonomously. This two-loop theory of skilled typewriting is supported by several previous studies (Crump \& Logan, 2010a, 2010b, 2010c; Liu, Crump, \& Logan, 2010; Logan, 2003; Logan \& Crump, 2009, 2010; Logan, Miller, \& Strayer, 2011; Snyder \& Logan, in press), and it provides a framework for interpreting typing performance in terms of the underlying control processes (Yamaguchi et al., 2013; Yamaguchi, Logan, \& Li, in press).

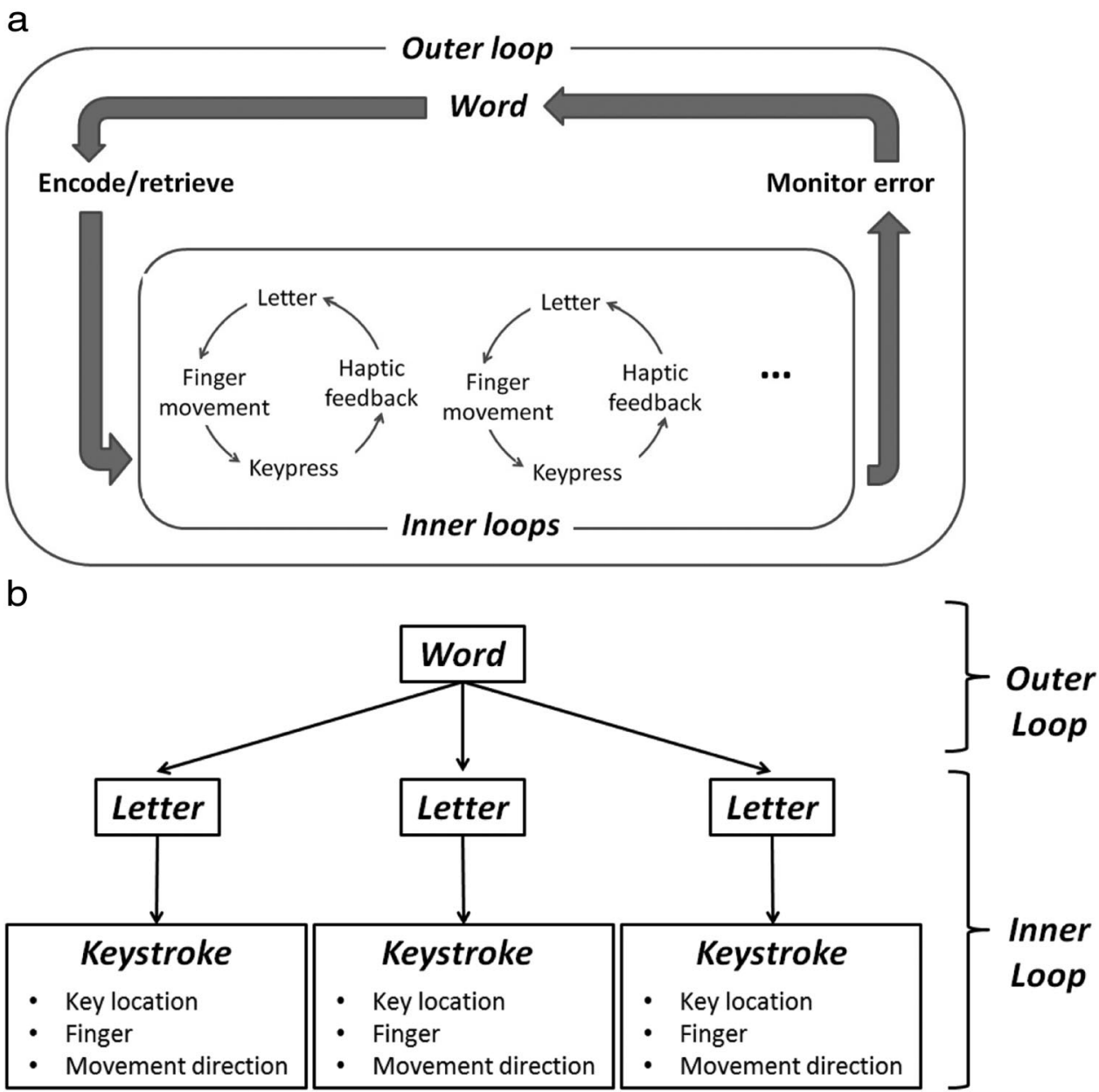

Figure 1. The two-loop theory of skilled typewriting: (a) schematic illustrations of control loops, and (b) processing units in the outer loop and the inner loop. 


\section{Pushing Typists Back on the Learning Curve}

Hierarchical control is acquired through training (Bryan \& Harter, 1899; Fitts \& Posner, 1967; Leonard \& Newman, 1964; MacKay, 1982; Pew, 1974; Rhodes et al., 2004; Verwey, 1996; Verwey, 1999). Thus, one strategy for studying hierarchical control in skilled typing is to compare novice and skilled typists. Fortunately, skilled typing is pervasive in modern society, but unfortunately, most people learn to type when they are children (Logan \& Crump, 2011). Thus, comparisons between novice and skilled typists would be confounded by large differences in cognitive and neurological development that would be hard to disentangle. We adopted a different strategy: We manipulated the materials typists typed and the keyboard they typed on to disable the associations that support skilled typing. Our manipulations were intended to push skilled typists back on the learning curve ${ }^{1}$, so that they can no longer utilize their skill. This allows us to examine skilled and unskilled typing in the same typists, avoiding the confounds involved in comparing true novices with skilled adults.

We suggest that typing skill relies on three kinds of association (see Figure 1b), and typists can be pushed back on the learning curve by disabling each kind of association. Typing relies on (a) associations between words and letters, which allow concurrent processing of letters (Crump \& Logan, 2010b; Logan et al., 2011); (b) associations between letters and keys, which support implicit knowledge about key locations (Liu et al., 2010; Logan, 2003), and (c) associations between keys and finger movements, which enable the inner loop to direct the fingers to the corresponding keys (Crump \& Logan, 2010a). The experiments we report in this article degraded typing skill by disabling two of these associations (word-letter and key-finger associations) and asked what levels of chunking were altered by doing so.

Associations between words and letters can be disabled by scrambling the order of letters in words (Fendrick, 1937; Shaffer, 1973; Shaffer \& Hardwick, 1968; Thomas \& Jones, 1970; West \& Sabban, 1982). Scrambling letter order prevents chunking of letters into larger units. This pushes skilled typists back on the learning curve by requiring serial processing of individual letters, as in the hunt-and-peck typing style of novice typists. Scrambling letter order may affect several levels of processing in skilled typing. It affects perceptual chunking: familiar words are encoded as single, unitized entities rather than collections of distinct letters (e.g., McClelland \& Johnston, 1977; McClelland \& Rumelhart, 1981; Reicher, 1969). Scrambling letter order may affect chunking in short-term memory (STM); familiar words are retained as single objects rather than sets of separate objects (e.g., Miller, 1956; Murdock, 1961). Scrambling letter order may affect chunking in motor planning; familiar words activate their constituent keystrokes in parallel rather than in series (Crump \& Logan, 2010b; Logan, 2003; Logan et al., 2011). Scrambling letter order may affect chunking in execution of keystrokes; familiar words allow production of familiar sequences of keystrokes that are produced as a group (e.g., Gentner, Larochelle, \& Grudin, 1988; Sakai, Kitaguchi, \& Hikosaka, 2003; Verwey, 1996). We examined chunking at these levels of typing by having skilled typists type words and scrambled words (nonwords).

Associations between keys and finger movements can be disabled by altering the haptic feedback from the keyboard that supports finger movements (Crump \& Logan, 2010c; Gordon \&
Soechting, 1995). We altered haptic feedback with a laser keyboard that projected an image of the QWERTY layout on a flat surface and registered keystrokes when typists touched the surface. The laser keyboard removes the feel of the keys and the resistance of the keys as typists type, making it harder for them to align their fingers and navigate on the keyboard. The laser keyboard slows skilled typing substantially (Crump \& Logan, 2010a, 2010b). We assume that altering haptic feedback disables associations between keys and finger movements, and this pushes skilled typists back on the learning curve, requiring them to pay attention to individual keystrokes like hunt-and-peck typists. Altering haptic feedback may affect chunking in motor planning because it focuses attention on individual keystrokes and distracts it from familiar sequences. Altering haptic feedback may also affect chunking in STM if it forces the outer loop to monitor individual keystrokes instead of familiar chunks. We examine these possibilities by using the laser keyboard (Crump \& Logan, 2010a, 2010c).

\section{The Present Study}

The present study focused on hierarchical control of skilled typewriting. The main purpose was to examine an essential characteristic of hierarchical control (chunking) at three levels of processing (perception, STM, and motor planning) by pushing skilled typists back on the learning curve. We used a discrete typing task to separate outer-loop processing from inner-loop processing (Logan \& Crump, 2011). The discrete typing task requires typists to type one letter string (word or nonword) on each trial as quickly as they can. It provides two separate latency measures that allow us to distinguish hierarchical from nonhierarchical control (see Figure 2): the interval between the onset of the string and the first keystroke (response time or reaction time [RT]) and the interval between successive keystrokes (interkeystroke interval or IKSI). If typing is controlled hierarchically, then RT reflects the time for outer loop and inner loop processing and IKSI reflects the time for inner loop processing. If typing is controlled nonhierarchically, then both RT and IKSI reflect the time for outer loop and inner loop processing.

In the first two experiments, we examined chunking at three levels of processing; perception, memory, and motor planning. Both experiments involved typing words and nonwords that varied in length. In Experiment 1, we focused on chunking in perception. We manipulated stimulus quality by adding noise (superimposing white lines on letter strings printed in black; see Figure 3), and observed the effect on RT and IKSI. In Experiment 2, we focused on chunking in STM. Skilled typists typed words and nonwords that varied in length (string length) while performing a concurrent memory load task, and we observed the effects on memory per-

\footnotetext{
${ }^{1}$ Schmidt and Lee (2005) defined motor learning as a process of acquiring the capability for producing skilled actions that occurs as a direct result of training, which produces relatively permanent changes in that capacity (see Magill, 2007; Salmoni, Schmidt, \& Walter, 1984). According to their view, a typical "learning curve," a plot of performance level as a function of trials, may not be a pure measure of learning because it also involves transient changes in performance such as fatigue and motivational factors. In the present usage of the term "learning curve," we assume that typists have acquired relatively permanent changes in the capacity for performing typing through prior experiences, and we intend to investigate the control processes underlying such changes by manipulating factors that would degrade the acquired skill.
} 


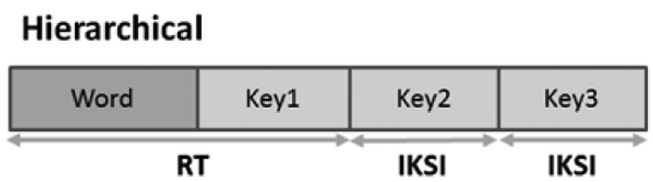

Non-hierarchical

\begin{tabular}{|c|c|c|c|c|c|}
\hline Letter1 & Key1 & Letter2 & Key2 & Letter3 & Key3 \\
\hline \multicolumn{2}{|c|}{ RT IKSI } \\
\multicolumn{2}{|c|}{ IKSI }
\end{tabular}

Figure 2. Hierarchical and nonhierarchical control of typing performance.

formance. In both Experiments 1 and 2, we examined chunking in motor planning. RT increases with the number of motor programs, or motor chunks, that need to be retrieved and loaded into a motor buffer (e.g., Henry \& Rogers, 1960; Klapp et al., 1979).

Experiments 3 and 4 investigated the effect of altering haptic feedback on hierarchical control in motor planning and STM. In Experiment 3, typists typed words and nonwords with a regular keyboard or a laser keyboard. We examined the number of motor chunks in typing with the two types of keyboard by looking at the string length effect on RT when typing words and nonwords. In Experiment 4, we used the concurrent memory load procedure of Experiment 2, requiring typists to type words with the regular and laser keyboards while retaining a concurrent memory load.

\section{Experiment 1}

Experiment 1 manipulated associations between words and letters by having typists type words and nonwords in order to investigate chunking in perception and motor planning. To examine chunking in perception, typists typed words and nonwords with and without a noise mask overlaid on the stimuli (see Figure 3). Noise affects stimulus encoding (Sternberg, 1969), and so should increase the latency of the outer loop but not the latency of the inner loop. Thus, when typing words, which allow chunking of letters, noise should increase RT, but not IKSI. When typing nonwords, which do not allow chunking of letters, noise should increase both RT and IKSI.

To examine chunking in motor planning, we varied the number of letters (string length) in words and nonwords to manipulate the number of motor chunks. RT increases with the number of motor chunks (Henry \& Rogers, 1960; Klapp et al., 1979; Rhodes et al., 2004; Sternberg, Monsell, Knoll, \& Wright, 1978; van Mier \& Hulstjin, 1993), so we expected longer RT with more motor chunks. If

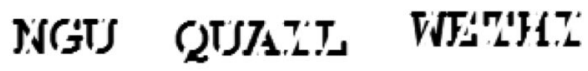

\section{KSFY JUITS NEKE}

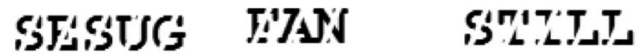

Figure 3. Examples of masked stimuli used in Experiment 1. words are typed as single chunks, there should be no string length effect in RT to words. If nonwords are typed as several motor chunks, then there should be a large string length effect in RT to nonwords (Sternberg et al., 1978). RT also increases with the size of motor chunks (Klapp, 1995), so it is possible that RT to words might increase with string length. However, this increase may be smaller than the increase in RT to nonwords.

\section{Method}

Subjects. Twenty-four undergraduate students at Vanderbilt University participated in the experiment. They received experimental credits toward their psychology courses for participation. All typists had English as their first language, and were touch-typists who were capable of typing with the conventional finger placements on the QWERTY keyboard. Typing rate was assessed at the beginning of each session with a typing test from Logan and Zbrodoff (1998) that involved copy typing a short paragraph. Mean typing rate was 82.80 words per minute $(W P M ; S E=3.05)$. The mean accuracy was $94.18 \%(S E=0.60)$. The typists reported having 4.64 months $(S E=$ 0.73 ) of formal training in typing on average and 10.33 years of typing experience $(S E=0.29)$. They also reported spending 4.33 hours $(S E=0.42)$ per day in front of computer.

Apparatus and stimuli. The apparatus consisted of a 19-in. color VGA monitor and a personal computer. Stimuli were words and nonwords, presented in 24 point Courier New font, printed in black against a white background. The words were obtained from the MRC Psycholinguistic Database (Coltheart, 1981; http://www .psych.rl.ac.uk/), consisting of 200 samples of 3-, 4-, or 5-letter words each. Mean word frequency per million was roughly equivalent across the three string lengths; $140.72(S E=24.25), 148.08$ (24.25), and 111.58 (18.80) for 3-, 4-, and 5-letter words, respectively, $F(2,297)<1, M S E=114.52$. The nonword stimuli were constructed by scrambling the order of letters in the word stimuli randomly; when this procedure resulted in another word or a familiar acronym, one of the letters was arbitrarily chosen and replaced with another letter whose key was located adjacent to the key for the original letter (e.g., the letter " $d$ " could be replaced by "s" or "f"; see Appendix for complete lists of words and nonwords used in the present experiment). The noise mask consisted of a string of seven "/" symbols arrayed horizontally to cover the entire word or nonword. The mask was printed in white (see Figure 3).

Procedure. The experiment was conducted individually for each typist in a cubicle under normal fluorescent lighting. Typists sat in front of the computer monitor at an unrestricted viewing 
distance of $55 \mathrm{~cm}$ and read on-screen instructions. Each typist performed two blocks of 12 practice trials, the first of which presented words and nonwords without the noise mask (no noise condition) and the second of which presented word and nonwords with the noise mask (noise condition). After these practice blocks, typists performed six blocks of 90 test trials, in which words and nonwords appeared equally frequently in a random order. The noise condition and the no noise condition were administered in separate blocks. The two conditions appeared in an alternating order. Half the typists performed the no noise block first, and the other half performed the noise block first. An experimental session took less than an hour.

Each trial started with a fixation cross at the center of screen, which lasted for $750 \mathrm{~ms}$. The cross was replaced by a word or nonword that consisted of three, four, or five letters, appearing in upper case. They appeared in the upper portion of the screen $(6.5$ $\mathrm{cm}$ above the screen center). Typists were instructed to type the material as quickly and as accurately as they could. Typed letters were echoed in lowercase $6.5 \mathrm{~cm}$ below the center of the screen immediately after each key was pressed because typists are used to seeing their keystrokes echoed in most interactions with computers. Skilled typists type at the same rate whether or not keystrokes are echoed (Diehl \& Seibel, 1962; Snyder, Logan \& Yamaguchi, 2013), but we decided to echo keystrokes to make the interaction with the experimental computer more familiar. When typing was completed or after 5,000 ms if typing was not complete, a feedback message appeared at the screen center. The message was "Correct" for correct trials, "Wrong!" for error trials, and "Too Slow" for trials where typists did not complete typing all the letters in the string. Trials were considered correct only if all letters were typed correctly. The feedback lasted for $500 \mathrm{~ms}$. The fixation cross replaced the feedback message to signal the next trial.

\section{Results}

Mean RT and IKSI for correct trials and percentage errors (PE) were computed for each typist and submitted to 2 (Stimulus Type; word vs. nonword) $\times 2$ (Stimulus Quality; noise vs. no noise) $\times$ 3 (String Length; 3, 4, 5 letters) ANOVAs. All variables were within-subject factors. The ANOVA results are summarized in Table 1. RT, IKSI, and PE are plotted in Figure 4. The differences we discuss below are significant in the relevant ANOVA unless noted otherwise. We present means across typists and the standard errors of those means.

Chunking in perception. Chunking in perception was assessed by examining the effect of stimulus noise on RT and IKSI for words and nonwords. We expected that noise would increase RT for words and nonwords, but increase only IKSI for nonwords. These predictions were confirmed, supporting chunking in perception.

RT was longer for nonwords $(M=774 \mathrm{~ms} ; S E=21)$ than for words $(M=636 ; S E=14)$, and it increased with noise $(M \mathrm{~s}=683$ vs. $727 \mathrm{~ms}$ for no noise and noise trials; SEs $=17$ and 18 , respectively). The effect of noise tended to be larger for nonwords $(M=51 \mathrm{~ms} ; S E=27)$ than for words $(M=37 \mathrm{~ms} ; S E=24)$, although the interaction did not reach significance. These results indicate that typing material and noise affected outer-loop processing, inner-loop processing, or both.

IKSI was longer for nonwords $(M=168 \mathrm{~ms} ; S E=6)$ than for words $(M=121 \mathrm{~ms} ; S E=3)$. IKSI also increased with noise, and the effect was larger for nonwords than for words; the interaction

Table 1

ANOVA Results for Response Times (RT), Interkeystroke Interval (IKSI), and Percentage Errors $(P E)$ in Experiment 1

\begin{tabular}{|c|c|c|c|c|c|}
\hline Factor & $d f$ & $F$ & $M S E$ & $p$ & $\eta_{p}^{2}$ \\
\hline & & & $\mathrm{RT}$ & & \\
\hline Stimulus Quality (SQ) & 1,23 & 129.07 & 1,071 & $<.001$ & .849 \\
\hline Stimulus Type (ST) & 1,23 & 277.62 & 4,933 & $<.001$ & .923 \\
\hline String Length (SL) & 2,46 & 66.14 & 881 & $<.001$ & .742 \\
\hline $\mathrm{SQ} \times \mathrm{ST}$ & 1,23 & 4.17 & 857 & .053 & .153 \\
\hline $\mathrm{SQ} \times \mathrm{SL}$ & 2,46 & 1.26 & 886 & .293 & .052 \\
\hline $\mathrm{ST} \times \mathrm{SL}$ & 2,46 & 20.91 & 554 & $<.001$ & .476 \\
\hline \multirow[t]{2}{*}{$\mathrm{SQ} \times \mathrm{ST} \times \mathrm{SL}$} & 2,46 & 2.76 & 621 & .074 & .107 \\
\hline & & & IKSI & & \\
\hline SQ & 1,23 & 13.89 & 201 & .001 & .377 \\
\hline ST & 1,23 & 188.28 & 836 & $<.001$ & .891 \\
\hline SL & 2,46 & 45.26 & 186 & .001 & .663 \\
\hline $\mathrm{SQ} \times \mathrm{ST}$ & 1,23 & 4.87 & 104 & .038 & .175 \\
\hline $\mathrm{SQ} \times \mathrm{SL}$ & 2,46 & 3.37 & 76 & .043 & .128 \\
\hline $\mathrm{ST} \times \mathrm{SL}$ & 2,46 & 51.54 & 110 & $<.001$ & .691 \\
\hline \multirow[t]{2}{*}{$\mathrm{SQ} \times \mathrm{ST} \times \mathrm{SL}$} & 2,46 & 2.53 & 63 & .091 & .099 \\
\hline & & & $\mathrm{PE}$ & & \\
\hline SQ & 1,23 & 9.72 & 11.98 & .005 & .297 \\
\hline ST & 1,23 & 110.49 & 8.57 & $<.001$ & .828 \\
\hline SL & 2,46 & 39.23 & 9.81 & $<.001$ & .630 \\
\hline $\mathrm{SQ} \times \mathrm{ST}$ & 1,23 & 7.48 & 11.85 & .012 & .246 \\
\hline $\mathrm{SQ} \times \mathrm{SL}$ & 2,46 & $<1$ & 15.56 & .925 & .003 \\
\hline $\mathrm{ST} \times \mathrm{SL}$ & 2,46 & $<1$ & 17.55 & .616 & .021 \\
\hline $\mathrm{SQ} \times \mathrm{ST} \times \mathrm{SL}$ & 2,46 & $<1$ & 15.40 & .662 & .018 \\
\hline
\end{tabular}



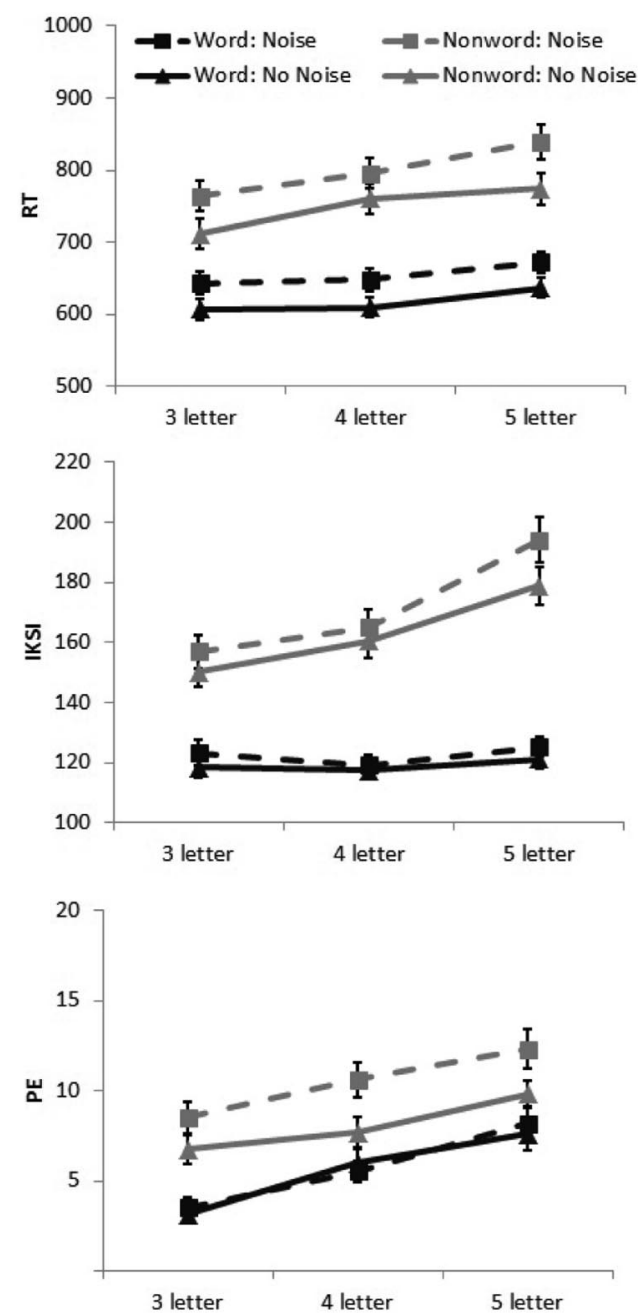

Figure 4. Mean response times (RT), interkeystroke interval (IKSI), and percentage errors $(\mathrm{PE})$ in Experiment 1 (error bars represent standard errors of the means)

was significant. The noise effect for nonwords $(M=9 \mathrm{~ms} ; S E=$ 2) was significant, $F(1,23)=15.16, M S E=187, p<.001, \eta_{p}^{2}=$ .397 , but the effect for words $(M=4 \mathrm{~ms} ; S E=2)$ did not reach significance, $F(1,23)=3.89, M S E=118, p=.061, \eta_{p}^{2}=.145$. The effect of noise on IKSI also increased with string length for nonwords but not for words (see Figure 4); the interaction between Stimulus Length and Stimulus Quality was only significant for nonwords, $F(2,46)=4.03, M S E=95, p=.024$, $\eta_{p}^{2}=.149$, but not for words, $F(2,46)<1, M S E=44, p=.480, \eta_{p}^{2}=.031$. The lack of the noise effect in IKSI for words suggests that noise affected the outer loop, and the presence of the noise effect in IKSI for nonwords implies that outer loop processing occurs in the middle of typing nonwords. Hence, the unit of encoding is larger for words than for nonwords, implying chunking in perception.

PE was larger for nonwords $(M=9.30 \% ; S E=0.44)$ than for words $(M=5.67 \%$; $S E=0.36)$. PE increased with noise for nonwords $(M \mathrm{~s}=8.11 \%$ and $10.49 \%$ without noise and with noise, respectively; $S E \mathrm{~s}=0.46$ and 0.60$)$ but not for words $(M \mathrm{~s}=5.59 \%$ and $5.76 \%$; SEs $=0.45$ and 0.45 ), which makes sense because encoding of words is supported from top-down process based on prior knowledge, but encoding of nonwords is not (McClelland \& Rumelhart, 1981).

Chunking in motor planning. Chunking in motor planning was assessed by examining the effect of string length on RT. We expected that RT would increase with string length, but the increase would be larger for nonwords than for words. This prediction was confirmed, supporting chunking in motor planning.

RT increased with string length, and the string-length effect was larger for nonwords $(M=35 \mathrm{~ms} / \mathrm{letter} ; S E=4)$ than for words $(M=15 \mathrm{~ms} / \mathrm{letter} ; S E=2)$. The larger string length effect on RT for nonwords supports the idea that there are more motor chunks in nonwords than in words of equivalent length. IKSI increased with string length for nonwords $(M=17 \mathrm{~ms} /$ letter; $S E=2)$ but not for words $(M=1 \mathrm{~ms} /$ letter; $S E=1)$. These outcomes are consistent with the idea that keystrokes are activated in series for nonwords, but keystrokes are activated in parallel for words, implying chunking in motor planning. PE increased for longer strings $(M \mathrm{~s}=$ $5.49 \%, 7.48 \%$, and $9.50 \%$ for 3, 4, and 5 letters; SEs $=0.38,0.43$, and 0.51 ), but the effect did not interact with other variables.

\section{Discussion}

Experiment 1 demonstrated chunking in perception by having skilled typists type words and nonwords to disable associations between words and letters. When typing words, noise disrupted RT but not IKSI. Noise increases encoding time (Sternberg, 1969), so the results indicate that RT includes encoding time, but IKSI does not, consistent with the idea that words are unitized perceptually (Reicher, 1969) and encoded as a chunk. When typing nonwords, noise disrupted both RT and IKSI. Thus, both RT and IKSI include encoding time, consistent with the idea that nonwords are encoded as multiple chunks. The results with nonwords suggest that typists did not encode all letters before they initiated the first keystroke, and then implemented them in series. If they had, there would not have been any effect of noise on IKSI. Thus, the present results indicate that skilled typists encode letters separately when they cannot chunk typing materials.

Experiment 1 also demonstrated chunking in motor planning. RT increased with string length, and the effect was larger for nonwords than for words. The results imply that there were more motor chunks for nonwords than for words. The string length effect on RT was the same with and without noise, suggesting that motor chunks are distinct from perceptual chunks. Thus, the string length effect on RT cannot be attributed to increased encoding time for longer letter strings. Also, string length affected IKSI for nonwords but not for words, which is also consistent with the idea that nonwords require more motor chunks than words.

\section{Experiment 2}

Experiment 2 disabled associations between words and letters to examine chunking in STM and its relation to chunking in motor planning. To examine chunking in STM, typists typed words and nonwords varying in length while performing a concurrent memory load task. Typists first memorized a letter string (word or nonword) and then a digit string. After the digit string extinguished, a go signal appeared, and typists typed the letters. Then they recalled the digits. STM capacity is limited (Cowan, 2001; 
Miller, 1956); therefore, the more chunks the typing task requires, the less capacity is available for retaining digits. We hypothesize that words are represented as single chunks regardless of their length, so there should be no string length effect on the accuracy of recalling digits when words are typed. We hypothesize that nonwords are represented as several chunks, so there should be a string length effect on the accuracy of recalling digits when nonwords are typed. Thus, the effect of string length on the accuracy of recalling digits can reveal chunking in the typing task.

We examined the relationship between chunking in STM and chunking in motor planning by evaluating the effect of concurrent memory load on typing performance (i.e., RT and IKSI). If both types of chunking are done in the outer loop, the string length effect should be larger with high memory load than with low memory load. If STM chunking is done in the outer loop and motor chunking is done in the inner loop, then the string length effect should be unaffected by memory load. The present experiment presented strings to be typed before the memory items, so the present procedure allowed typists sufficient time to encode words and nonwords before they started typing (Wright, Black, Immink, Brueckner, \& Magnuson, 2004; Yamaguchi et al., 2013). This excludes possible contributions of encoding to the string length effect in RT, and allows stronger claims about motor chunks than Experiment 1 .

\section{Method}

Subjects. A new group of 24 undergraduate students at Vanderbilt University participated in the present experiment to fulfill experiment credits for their psychology courses. All reported having normal or corrected-to-normal visual acuity and normal color vision. They had English as their native language and were capable of touch typing. Their mean typing speed was 83.32 WPM $(S E=3.12)$ and their mean accuracy was $93.21 \%(S E=0.84)$. On average, they had 4.78 months of formal training in typing $(S E=0.64)$ and 11.25 years of typing experiences $(S E=0.55)$. They reported spending 3.73 hours per day $(S E=0.36)$ in front of computer.

Apparatus and stimuli. The apparatus was identical with that used in Experiment 1. For the typing task, stimuli consisted of 3and 5-letter words and nonwords that were used in Experiment 1. For the concurrent memory task, stimuli were strings of five digits that were randomly chosen on each trial. For the low-load condition, five digits were identical (e.g., "22222"), and for the highload condition, five digits were unique (e.g., "94032"). The digits were presented in $18 \mathrm{pt}$. Courier New font, arrayed horizontally at the center of screen.

Procedure. The experiment was conducted individually in a cubicle. Each typist performed two blocks of 12 practice trials, for which the two lengths of words and nonwords occurred equally frequently in a random order. The first block was the low-load condition, and the second block was the high-load condition. These practice trials were not included in the analysis. The next eight blocks were composed of 60 test trials. Half the blocks were for the low-load condition, and the other half were for the highload condition. The two conditions were administered in an alternating order, and the order was counterbalanced across typists.

On each trial, typists were presented with a word or nonword, which remained on the screen for $500 \mathrm{~ms}$ and was replaced by a 750-ms blank screen. Then, a string of five (identical or unique) digits appeared for 1,000 ms, which was followed by a 500-ms blank screen. The message "GO!" occurred as a go signal to prompt typists to type the word or nonword as quickly and as accurately as they could. The go message was accompanied by a tone (800-Hz pitch, 500-ms duration) presented binaurally through headphones. The go signal occurred at the upper portion of the screen $(6.5 \mathrm{~cm}$ above the screen center) and was erased after 500 ms. Typed letters were echoed at the lower portion of the screen $(6.5 \mathrm{~cm}$ below the screen center) in lower case.

As 3,000 ms elapsed after the onset of the go signal, typists were prompted to enter the string of digits by the message "Enter the digits!" and typists used their right hand to enter digits on a number pad on the right side of the keyboard within a 5,000-ms time window. The entered digits were also echoed on the screen in the same manner as for the typing task. After the digit entry, feedback for the typing and memory tasks appeared at the upper and lower portions of the screen, respectively. For both tasks, the messages "Correct," "Error!," and "Too Slow," appeared for the correct, incorrect, and no responses, respectively. No response occurred when typists failed to complete typing or enter digits in the given time windows. For the typing task, a trial was considered correct only if all letters were typed correctly in the correct order. For the memory task, a trial was considered correct only if all digits were correctly entered in the correct order.

Each of the eight test blocks ended with the accuracy scores for the two tasks, which displayed the percentages of correct responses in that block separately for the two tasks. An experimental session lasted less than an hour.

\section{Results}

Mean RT and IKSI for correct responses for the typing task, and percentage errors for typing $\left(\mathrm{PE}_{\text {typing }}\right.$ ) were computed for each typist. Percentage error for recall $\left(\mathrm{PE}_{\text {recall }}\right)$ was computed for trials in which a word or nonword was typed correctly. The results are summarized in Figure 5. These dependent variables were submitted to 2 (Stimulus Type: word vs. nonword) $\times 2$ (String Length: 3 letter vs. 5 letter $) \times$ 2 (Memory Load: high vs. low) ANOVAs. As in Experiment 1, the differences described below are significant in the ANOVAs unless noted otherwise. The results are summarized in Table 2.

Chunking in STM. Chunking in STM was assessed by examining the effect of string length in the typing materials on $\mathrm{PE}_{\text {recall }}$. We expected that $\mathrm{PE}_{\text {recall }}$ would be larger for longer strings than for shorter strings, but this influence of string length would be more pronounced for nonwords than for words. The results confirmed this prediction, supporting chunking in STM.

$\mathrm{PE}_{\text {recall }}$ was larger for nonwords $(M=19.11 \% ; S E=1.64)$ than for words $(M=7.58 \%$; $S E=0.94)$. It also depended on string length, and the string length effect was larger for nonwords $(M \mathrm{~s}=$ $10.79 \%$ vs. $27.43 \%$ for 3 and 5 letters; $S E$ s $=1.34$ and 2.22 ) than for words $(M \mathrm{~s}=5.97 \%$ vs. $9.18 \%$ for 3 and 5 letters; $S E \mathrm{~s}=0.84$ and 1.20). These patterns were more pronounced for the high memory load condition than for the low memory load condition (see Figure 5). These results indicate that the units of STM representation are larger for typing words than for typing nonwords, implying chunking in STM.

Dissociation between STM and motor chunks. To assess whether chunking in STM was the same as chunking in motor planning, we examined whether the string length effect on RT (the index of motor chunking) would depend on memory load (the 

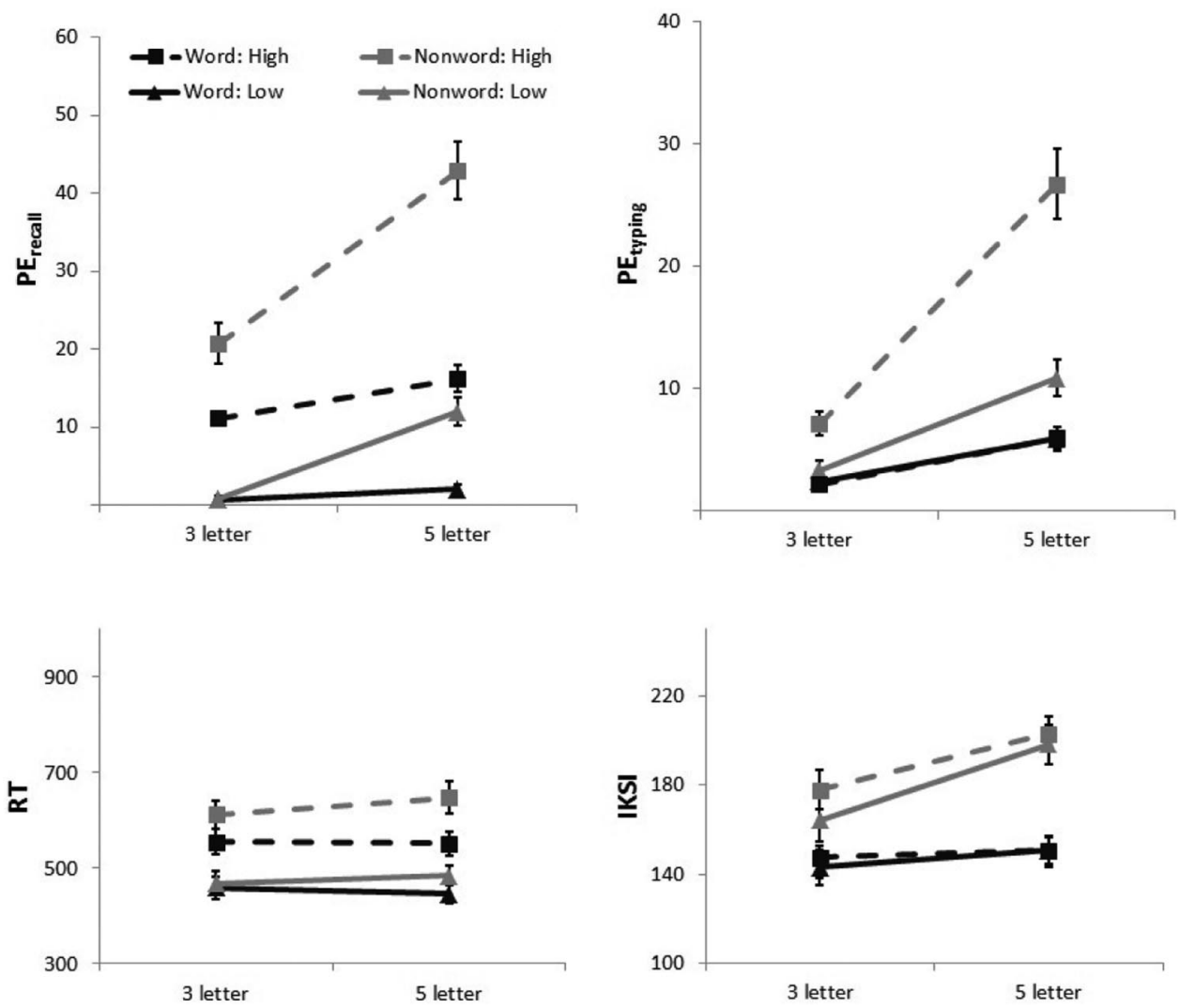

Figure 5. Mean percentage errors in recall $\left(\mathrm{PE}_{\text {recall }}\right)$, percentage errors in typing $\left(\mathrm{PE}_{\text {typing }}\right)$, response times (RT), and interkeystroke interval (IKSI) in Experiment 2 (error bars represent standard errors of the means).

index of STM). We expected that the string length effect would be larger for the high memory load if chunking in STM is the same as chunking in motor planning, but the string length effect would be the same for high and low memory loads if chunking in STM is dissociable from chunking in motor planning. The results supported the dissociation between chunking in STM and chunking in motor planning.

For RT, there was a string length effect for typing nonwords $(M=13 \mathrm{~ms} /$ letter; $S E=5.81)$ but not for typing words $(M=-4$ $\mathrm{ms}$ /letter; $S E=4.62$ ), suggesting a greater number of motor chunks for nonwords than for words. These outcomes are consistent with Experiment 1. The string length effects were smaller here than in Experiment 1 because the preexposure of the strings allowed typists to partially complete motor planning before the go signal occurred (see Klapp, 1995; Wright et al., 2004; Yamaguchi et al., 2013). A portion of the string length effect in Experiment 1 could have been due to longer encoding for longer strings, but preexposure of the strings excluded this possibility in the present experiment. Memory load increased RT, and the increase was larger for nonwords $(M \mathrm{~s}=476 \mathrm{~ms}$ vs. $629 \mathrm{~ms}$ for low and high loads; $S E \mathrm{~s}=22$ and 22) than for words $(M \mathrm{~s}=453 \mathrm{~ms}$ vs. $553 \mathrm{~ms}$ for low and high loads; $S E \mathrm{~s}=31$ and 25$)$. However, the string length effect did not differ statistically between low and high memory conditions for words $(M \mathrm{~s}=-6 \mathrm{~ms} / \mathrm{letter}$ and $-1 \mathrm{~ms} /$ letter for high and low memory loads, respectively) or for nonwords $(M \mathrm{~s}=8 \mathrm{~ms} /$ letter and $18 \mathrm{~ms} /$ letter $)$, dissociating motor chunks from STM.
For IKSI, the string length effect was also larger for nonwords $(M=15 \mathrm{~ms} / \mathrm{letter} ; S E=2)$ than for words $(M=3 \mathrm{~ms} /$ letter; $S E=$ 1). These results are consistent with Experiment 1. There was little effect of memory load on IKSI for words $(M \mathrm{~s}=147 \mathrm{~ms}$ vs. 149 $\mathrm{ms} ; S E \mathrm{~s}=7$ and 6) or nonwords $(M \mathrm{~s}=181 \mathrm{~ms}$ vs. $190 \mathrm{~ms}$ for low and high loads; SEs $=9$ and 8). The string length effect did not differ between low and high memory load conditions for words $(M \mathrm{~s}=4 \mathrm{~ms} /$ letter and $2 \mathrm{~ms} / \mathrm{letter}$ for high and low memory loads, respectively) or for nonwords $(M \mathrm{~s}=17 \mathrm{~ms} /$ letter and $13 \mathrm{~ms} /$ letter). The results imply dissociation between motor chunks from STM, which is consistent with previous studies that suggested a distinction between input and output buffers (e.g., FitzGerald, Tattersall, \& Broadbent, 1988; Tattersal \& Broadbent, 1991).

$\mathrm{PE}_{\text {typing }}$ depended on all of the three variables (see Figure 5): Most notably, high memory load increased $\mathrm{PE}_{\text {typing }}$ for nonwords $(M \mathrm{~s}=7.13 \%$ vs. $16.97 \%$ for low and high loads; $S E \mathrm{~s}=0.95$ and 1.71 ), but not for words $(M \mathrm{~s}=4.19 \%$ vs. $4.11 \%$ for low and high loads; $S E s=0.57$ and 0.49$)$. Also, high memory load increased the string length effect for nonwords, but it did not affect the string length effect for words. Thus, STM load increased with string length for nonwords but not for words, again suggesting units of STM are larger for words than for nonwords.

\section{Discussion}

Experiment 2 demonstrated that the units of STM representation are larger for words than for nonwords, implying chunking in 
Table 2

ANOVA Results for Percent Recall Errors ( $\left.P E_{\text {Recall }}\right)$, Response Times $(R T)$, Interkeystroke Interval (IKSI), and Percent Typing Errors $\left(P E_{\text {Typing }}\right)$ in Experiment 2

\begin{tabular}{|c|c|c|c|c|c|}
\hline Factor & $d f$ & $F$ & MSE & $p$ & $\eta_{p}^{2}$ \\
\hline & & & $\mathrm{PE}_{\text {recall }}$ & & \\
\hline Stimulus Type (ST) & 1,23 & 83.63 & 76.35 & $<.001$ & .784 \\
\hline Memory Load (ML) & 1,23 & 77.51 & 219.86 & $<.001$ & .771 \\
\hline String Length (SL) & 1,23 & 103.88 & 45.48 & $<.001$ & .819 \\
\hline $\mathrm{ST} \times \mathrm{ML}$ & 1,23 & 37.56 & 54.41 & $<.001$ & .620 \\
\hline $\mathrm{ST} \times \mathrm{SL}$ & 1,23 & 61.36 & 35.30 & $<.001$ & .727 \\
\hline $\mathrm{SL} \times \mathrm{ML}$ & 1,23 & 22.49 & 28.98 & $<.001$ & .494 \\
\hline \multirow[t]{2}{*}{$\mathrm{ST} \times \mathrm{ML} \times \mathrm{SL}$} & 1,23 & 6.45 & 24.75 & .018 & .219 \\
\hline & & & RT & & \\
\hline ST & 1,23 & 51.17 & 2,307 & $<.001$ & .690 \\
\hline ML & 1,23 & 30.07 & 25,732 & $<.001$ & .567 \\
\hline SL & 1,23 & 1.26 & 3,021 & .273 & .052 \\
\hline $\mathrm{ST} \times \mathrm{ML}$ & 1,23 & 18.03 & 1,835 & $<.001$ & .439 \\
\hline $\mathrm{ST} \times \mathrm{SL}$ & 1,23 & 5.65 & 2,382 & .026 & .197 \\
\hline $\mathrm{SL} \times \mathrm{ML}$ & 1,23 & 1.50 & 1,697 & .233 & .061 \\
\hline \multirow[t]{2}{*}{$\mathrm{ST} \times \mathrm{ML} \times \mathrm{SL}$} & 1,23 & $<1$ & 1,714 & .697 & .007 \\
\hline & & & IKSI & & \\
\hline ST & 1,23 & 158.79 & 432 & $<.001$ & .873 \\
\hline ML & 1,23 & $<1$ & 1,572 & .330 & .041 \\
\hline SL & 1,23 & 34.16 & 429 & $<.001$ & .598 \\
\hline $\mathrm{ST} \times \mathrm{ML}$ & 1,23 & 6.06 & 93 & .022 & .209 \\
\hline $\mathrm{ST} \times \mathrm{SL}$ & 1,23 & 42.75 & 163 & $<.001$ & .650 \\
\hline $\mathrm{SL} \times \mathrm{ML}$ & 1,23 & 2.55 & 191 & .124 & .100 \\
\hline \multirow[t]{2}{*}{$\mathrm{ST} \times \mathrm{ML} \times \mathrm{SL}$} & 1,23 & $<1$ & 176 & .545 & .016 \\
\hline & & & $\mathrm{PE}_{\text {typing }}$ & & \\
\hline ST & 1,23 & 52.82 & 56.67 & $<.001$ & .697 \\
\hline ML & 1,23 & 50.4 & 22.66 & $<.001$ & .687 \\
\hline SL & 1,23 & 73.38 & 49.23 & $<.001$ & .759 \\
\hline $\mathrm{ST} \times \mathrm{ML}$ & 1,23 & 53.35 & 22.15 & $<.001$ & .699 \\
\hline $\mathrm{ST} \times \mathrm{SL}$ & 1,23 & 25.52 & 46.23 & $<.001$ & .526 \\
\hline $\mathrm{SL} \times \mathrm{ML}$ & 1,23 & 23.32 & 19.27 & $<.001$ & .503 \\
\hline $\mathrm{ST} \times \mathrm{ML} \times \mathrm{SL}$ & 1,23 & 27.42 & 15.30 & $<.001$ & .544 \\
\hline
\end{tabular}

STM. This conclusion is supported by the higher recall error rate, and the larger effect of string length on recall errors, for nonwords than for words. There was an effect of string length on recall errors not only for nonwords but also for words. This suggests that the units of STM representation for typing words may be smaller than words (e.g., syllables), or it may reflect differential decay of STM (e.g., Barrouillet \& Camos, 2012), given that it takes longer to type longer words than shorter ones (i.e., longer words may prevent rehearsal more than shorter words). In either case, the increase of recall error per letter was very small for words (1.07\%), as compared with nonwords $(5.55 \%)$, suggesting that the number of letters in words had only a minor impact on recall performance. Also, the present experiment dissociated the effect of STM load from the effect of string length in both RT and IKSI. This finding implies that two types of chunking are involved at different levels of skilled typewriting (Smyth \& Pendleton, 1989; Tattersall \& Broadbent, 1991), presumably one in the outer loop and the other in the inner loop.

To summarize, Experiments 1 and 2 provided novel evidence revealing chunking in three levels of processing in skilled typing; perception, STM, and motor planning. The results of the experiments imply that hierarchical control depends on associations between words and letters, which allow chunking of component processes recruited for typing familiar words. When typing unfamiliar nonwords, the same component processes may be recruited for the constituent letters, but they cannot operate in parallel. Thus, the utilization of hierarchical control depends on typing materials.

\section{Experiment 3}

Experiment 3 disabled associations between fingers and keys by having skilled typists type on a laser keyboard that projected an image of the keys on a tabletop and registered responses when typists' fingers struck the tabletop. The laser keyboard is similar to the keyboards on touch-screen devices (e.g., tablet PCs and smartphones), which many users find difficult to type on. Consistent with this common complaint, typing is much slower and less accurate with the laser keyboard (Crump \& Logan, 2010c). Compared with a normal keyboard, typing on a laser keyboard increases RT by $50 \%$ and IKSI by $100 \%$, and there is little change in the disruption after 400 trials of practice (Crump \& Logan, 2010a, 2010c). We assume the disruption occurs, not simply because typists are unfamiliar with the laser keyboard, but because the laser keyboard alters the haptic feedback to the fingers that is 
usually present when typing on a normal keyboard, removing the feel of the keys and the resistance of the keys that are important in aligning the fingers with the keyboard and controlling finger movements (Crump \& Logan, 2010a, 2010c; Gordon \& Soechting, 1995). The goal of Experiment 3 was to determine whether the laser keyboard also disrupts hierarchical control of typing by disabling chunking in motor planning. We evaluated explanations of slower typing, one that assumes hierarchical control is disrupted and one that does not.

First, altering haptic feedback might force the outer loop to take control of typing away from the inner loop, controlling the execution of each keystroke. This would slow RT and IKSI, as observed. Outer-loop control of individual keystrokes would destroy motor chunking, decomposing chunks into strings of letters. Words should be typed like nonwords, whose hierarchical control is already compromised. Thus, with the laser keyboard, words should be typed as slowly as nonwords, and the effect of string length should be as large for words as for nonwords.

Second, altering haptic feedback might force the outer loop to monitor each keystroke, looking at the fingers to be sure that they struck the right key and looking at the screen to be sure that the keystroke was registered. This would also slow RT and IKSI, as observed (Logan \& Crump, 2009; Snyder \& Logan, in press). The inner loop could still control the selection and execution of each keystroke, although at a slower rate. Thus, motor chunking would still be preserved. Words would be typed faster than nonwords, and the string length effect would be larger for nonwords than for words.

In addition, we also examined how altering haptic feedback influences posterror slowing (longer IKSI for keystroke that immediately follow an error keystroke; e.g., Shaffer, 1975a) with the laser keyboard to that with the regular keyboard. Previous research suggests that typewriting involves two error detection mechanisms, an outer-loop mechanism that monitors the letters echoed on the screen for errors, and an inner-loop mechanism that monitors finger movements (Logan \& Crump, 2010; Snyder et al., 2013). Posterror slowing is associated with the inner-loop mechanism. Thus, we expect posterror slowing for words and nonwords with regular and laser keyboards because all these conditions involve the inner loop. The regular and laser keyboards may engage different motives for posterror slowing. The laser keyboard may engage a "prevention" motive (Crump \& Logan, in press), in which typing is slower for several keystrokes after an error to reduce the likelihood of further errors. Errors are more prevalent with the laser keyboard and can be prevented by slowing down. The regular keyboard may engage a "cure" motive (Crump \& Logan, in press), in which typing is slower immediately after an error when typists must inhibit their natural tendency to correct errors. Errors are less prevalent with the regular keyboard and skilled typists may feel no need to adjust the speed-accuracy trade-off (although they can if they are required to; Yamaguchi et al., 2013).

\section{Method}

Subjects. A new group of 24 touch typists were recruited from the Vanderbilt University community. All typed with the conventional finger placements on the QWERTY keyboard. Four typists received experimental credits toward their psychology courses, and the remaining typists were paid $\$ 12$ for participation. The mean typing speed and accuracy in the typing test were 85.84 WPM $(S E=3.66)$ and $94.66 \%(S E=0.77)$, respectively. These typists reported having 5.27 months $(S E=0.75)$ of formal training and 11.42 years $(S E=0.78)$ of typing experience, and spending 4.65 hours per day $(S E=0.48)$ in front of computer.

Apparatus, stimuli, and procedure. The apparatus was the same as those of the preceding experiments. Stimuli were the 3-, 4-, and 5-letter words and nonwords that were also used in Experiment 1 . The task was also similar to that of Experiment 1 without the noise mask. Each typist performed two separate sets of trials, each consisting of one block of 12 practice trials and four blocks of 90 test trials, in which all combinations of string length and stimulus type were intermixed randomly. Typists initiated each block by pressing the space bar. In one of the two sets of trials, typists used the regular keyboard to perform the task; in the other, they used the laser-projection keyboard (Golan Technology, Brooklyn, NY), which was used in Crump and Logan's (2010a, 2010c) studies. Half the typists used the regular keyboard in the first block and the laser-projection keyboard in the second block; the order was reversed for the other half. The procedure closely followed that of Experiment 1 in other respects.

\section{Results}

Mean RT and IKSI for correct responses and PE were computed for each typist (see Figure 6) and submitted to 2 (Keyboard: regular vs. laser) $\times 2$ (Stimulus Type: word vs. nonword) $\times 3$ (String Length: 3, 4, and 5 letters) ANOVAs. The results are summarized in Table 3. Again, differences discussed below are significant in the ANOVAs unless noted otherwise.

Chunking in typing words and nonwords. To examine whether altering haptic feedback disabled hierarchical control, we first examined whether words were typed like nonwords with the laser keyboard. Typing was slower with the laser keyboard, but words were still typed faster than nonwords, suggesting that the laser keyboard did not disable hierarchical control.

RT increased nearly by $50 \%$ with the laser keyboard $(M=997$ $\mathrm{ms} ; S E=18)$ as compared with the regular keyboard $(M=668$ $\mathrm{ms} ; S E=17)$. Nevertheless, RT was shorter for words than for nonwords with the regular keyboard $(M \mathrm{~s}=611 \mathrm{vs} .725 \mathrm{~ms}$ for words and nonwords; SEs $=13$ and 22) and with the laser keyboard $(M \mathrm{~s}=942$ vs. $1,052 \mathrm{~ms}$ for words and nonwords; $S E \mathrm{~s}=$ 16 and 21), and the advantage for the words did not differ between the two keyboard types. Overall, RT was shorter for words $(M=$ $611 \mathrm{~ms} ; S E=12)$ than for nonwords $(M=725 \mathrm{~ms} ; S E=18)$. These outcomes suggest that, even with the laser keyboard, units of typing are still larger for words than for nonwords.

IKSI increased by $145 \%$ with the laser keyboard $(M=384 \mathrm{~ms}$; $S E=20)$ as compared with the regular keyboard $(M=157 \mathrm{~ms}$; $S E=7)$. IKSI was still shorter for words than for nonwords with the laser keyboard. The difference between words and nonwords was smaller with the laser keyboard ( $M s=368$ vs. $401 \mathrm{~ms}$ for words and nonwords; SEs $=21$ and 20; difference $=33 \mathrm{~ms}$ ), than with the regular keyboard $(M \mathrm{~s}=134$ vs. $180 \mathrm{~ms} ; S E \mathrm{~s}=6$. and 9; difference $=46 \mathrm{~ms}$ ). We suggest that nonwords increased IKSI for the laser keyboard less than it did for the regular keyboard due to 

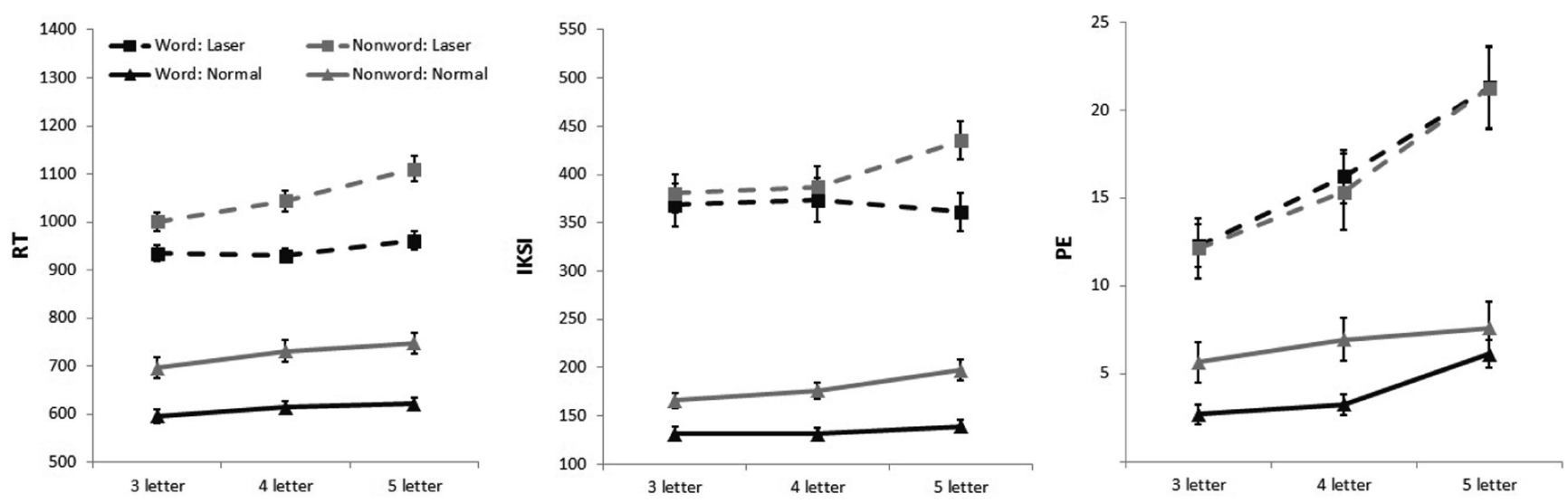

Figure 6. Mean response times (RT), interkeystroke interval (IKSI), and percentage errors (PE) in Experiment 3 (error bars represent standard errors of the means).

"cognitive slack" (Pashler, 1998; Yamaguchi et al., in press). ${ }^{2}$ The IKSI results suggest that units of typing are still larger for words than for nonwords when typing with the laser keyboard.

PE increased with the laser keyboard $(M=5.37 \%$ and $16.41 \%$ for the regular and laser keyboards, respectively; $S E \mathrm{~s}=0.74$ and 1.56). With the regular keyboard, $\mathrm{PE}$ was larger for nonwords $(M=6.73 \% ; S E=4.01)$ than for words $(M=4.01 \% ; S E=6.73)$, but the difference disappeared with the laser keyboard $(M \mathrm{~s}=$ $16.59 \%$ and $16.23 \%$ for words and nonwords; SEs $=1.42$ and 1.85). These results are consistent with the findings that typing errors depend primarily on the inner loop operations (Yamaguchi et al., 2013).

Chunking in motor planning. Chunking in motor planning was also assessed by examining the string length effect on RT for words and nonwords. If altering haptic feedback decomposed motor chunks, we expected that the string length effect would be as large for words as for nonwords. The string length effect was still larger for nonwords, corroborating the earlier conclusion that the laser keyboard did not affect hierarchical control in typing words.

RT increased with string length. However, for words, the string length effect did not differ between the regular keyboard $(M=13$ $\mathrm{ms} / \mathrm{letter} ; S E=3)$ and the laser keyboard $(M=13 \mathrm{~ms} / \mathrm{letter} ; S E=$ 4). Thus, the laser keyboard did not increase the number of motor chunks. For nonwords, the string length effect was smaller with the regular keyboard $(M=26 \mathrm{~ms} / \mathrm{letter} ; S E=5)$ than with the laser keyboard $(M=55 \mathrm{~ms} / \mathrm{letter} ; S E=9)$. This difference was mainly attributable to the longer RT for 5-letter nonwords. Possibly, typists may have encoded more letters before typing with the laser keyboard because they needed to shift their eyes from the screen to their hands to monitor their typing.

IKSI also increased with string length. For words, the string length effect was not larger for the laser keyboard $(M=-4$ $\mathrm{ms} / \mathrm{letter} ; S E=4)$ than for the regular keyboard $(M=4 \mathrm{~ms} / \mathrm{letter}$; $S E=1$ ), suggesting that the laser keyboard did not increase the number of motor chunks. For nonwords, the string length effect was larger for the laser keyboard $(M=27 \mathrm{~ms} / \mathrm{letter} ; S E=4)$ than for the regular keyboard $(M=16 \mathrm{~ms} / \mathrm{letter} ; S E=3)$, perhaps because the outer loop had to monitor keystrokes.

For PE, the effect of string length was larger with the laser keyboard $(M \mathrm{~s}=12.20 \%, 15.76 \%$, and $21.27 \%$, for 3, 4 and 5 letters; SEs
$=1.37,1.68$, and 2.04) than with the regular keyboard $(M \mathrm{~s}=4.17 \%$, $5.09 \%$, and 6.85\%; SEs $=0.80,0.79$, and 1.03 ), reflecting the increased probability of making error for each keystroke.

Posterror slowing. To examine the role of haptic feedback in detection of errors, we computed IKSI for error trials as a function of keystroke positions relative to error keystroke. Figure 7 shows mean IKSI collapsed across three string lengths and typists. To index the magnitude of posterror slowing, we subtracted the IKSI for keystrokes that immediately preceded the error keystroke (E 1) from the IKSI for keystrokes that immediately followed the error keystroke $(E+1)$. Two typists were excluded from the analysis because they had an empty cell in one of the regular keyboard conditions (either for word or nonword trials). We submitted the posterror slowing scores for the remaining 22 typists to a 2 (Stimulus Type: word vs. nonword) $\times 2$ (Keyboard Type: regular vs. laser) ANOVA, which only revealed a significant main effect of Keyboard Type, $F(1,21)=14.00, M S E=26,796, p<$ $.001, \eta_{p}^{2}=.400$. Posterror slowing was larger with the regular keyboard $(M=393 \mathrm{~ms} ; S E=33)$ than with the laser keyboard $(M=263 \mathrm{~ms} ; S E=32)$, suggesting that posterror slowing occurred for different reasons for the two keyboards.

Next, we examined the persistence of posterror slowing by subtracting IKSI for $\mathrm{E}+2$ from IKSI for $\mathrm{E}+1$. We excluded two additional typists who also had an empty cell in one of the regular keyboard conditions, and submitted the remaining 20 typists'

\footnotetext{
${ }^{2}$ With words, the outer loop is only engaged for the first keystroke, so it affects RT but not IKSI. IKSI depends only on inner-loop processing. With nonwords, the outer loop is engaged for all keystrokes, affecting IKSI as well as RT. The outer loop and inner loop can go on in parallel, so the outer loop can prepare keystroke $\mathrm{N}+1$ while the inner loop executes keystroke N. We assume that outer loop processing takes longer than inner loop processing with the regular keyboard, so the inner loop has to wait for the outer loop to prepare the next keystroke. This waiting time is called "cognitive slack" (Pashler, 1998). We assume that the laser keyboard prolongs inner loop processing, increasing IKSI for words and nonwords. This increase in inner-loop processing time reduces cognitive slack for nonwords, reducing the amount of time the inner loop has to wait for the outer loop to finish before it can start to execute the next keystroke. Thus, the difference in IKSI for words and nonwords will be smaller for the laser keyboard than for the regular keyboard, as observed (see also Yamaguchi, Logan, \& $\mathrm{Li}$, in press).
} 
Table 3

ANOVA Results for Response Times (RT), Interkeystroke Interval (IKSI), and Percentage Errors $(P E)$ in Experiment 3

\begin{tabular}{|c|c|c|c|c|c|}
\hline Factor & $d f$ & $F$ & $M S E$ & $p$ & $\eta_{p}^{2}$ \\
\hline & & & $\mathrm{PE}_{\text {recall }}$ & & \\
\hline Keyboard Type (KT) & 1,23 & 4.52 & 35.32 & .044 & .164 \\
\hline Memory Load (ML) & 1,23 & 51.08 & 170.31 & $<.001$ & .690 \\
\hline String Length (SL) & 1,23 & 33.39 & 17.50 & $<.001$ & .592 \\
\hline $\mathrm{KT} \times \mathrm{ML}$ & 1,23 & $<1$ & 28.77 & .554 & .015 \\
\hline $\mathrm{KT} \times \mathrm{SL}$ & 1,23 & $<1$ & 34.27 & .648 & .009 \\
\hline $\mathrm{SL} \times \mathrm{ML}$ & 1,23 & 11.2 & 17.18 & .003 & .327 \\
\hline \multirow[t]{2}{*}{$\mathrm{KT} \times \mathrm{ML} \times \mathrm{SL}$} & 1,23 & $<1$ & 20.39 & .608 & .012 \\
\hline & & & RT & & \\
\hline KT & 1,23 & 64.78 & 36,346 & $<.001$ & .738 \\
\hline ML & 1,23 & 71.07 & 26,741 & $<.001$ & .756 \\
\hline SL & 1,23 & $<1$ & 1,800 & .687 & .007 \\
\hline $\mathrm{KT} \times \mathrm{ML}$ & 1,23 & 12.82 & 12,052 & .002 & .358 \\
\hline $\mathrm{KT} \times \mathrm{SL}$ & 1,23 & $<1$ & 874 & .472 & .023 \\
\hline $\mathrm{SL} \times \mathrm{ML}$ & 1,23 & $<1$ & 1,294 & .676 & .008 \\
\hline \multirow[t]{2}{*}{$\mathrm{KT} \times \mathrm{ML} \times \mathrm{SL}$} & 1,23 & $<1$ & 2,716 & .761 & .004 \\
\hline & & & IKSI & & \\
\hline KT & 1,23 & 233.74 & 6,305 & $<.001$ & .910 \\
\hline ML & 1,23 & 3.02 & 1,124 & .095 & .116 \\
\hline $\mathrm{SL}$ & 1,23 & 10.00 & 350 & .004 & .303 \\
\hline $\mathrm{KT} \times \mathrm{ML}$ & 1,23 & 1.99 & 521 & .171 & .080 \\
\hline $\mathrm{KT} \times \mathrm{SL}$ & 1,23 & 20.59 & 438 & $<.001$ & .472 \\
\hline $\mathrm{SL} \times \mathrm{ML}$ & 1,23 & 1.85 & 207 & .188 & .074 \\
\hline \multirow[t]{2}{*}{$\mathrm{KT} \times \mathrm{ML} \times \mathrm{SL}$} & 1,23 & 1.97 & 208 & .174 & .079 \\
\hline & & & $\mathrm{PE}_{\text {typing }}$ & & \\
\hline KT & 1,23 & 30.79 & 158.23 & $<.001$ & .572 \\
\hline ML & 1,23 & 3.61 & 28.85 & .070 & .136 \\
\hline SL & 1,23 & 87.63 & 23.71 & $<.001$ & .792 \\
\hline $\mathrm{KT} \times \mathrm{ML}$ & 1,23 & $<1$ & 36.57 & .759 & .004 \\
\hline $\mathrm{KT} \times \mathrm{SL}$ & 1,23 & 11.48 & 32.78 & .003 & .333 \\
\hline $\mathrm{SL} \times \mathrm{ML}$ & 1,23 & $<1$ & 21.81 & .860 & .001 \\
\hline $\mathrm{KT} \times \mathrm{ML} \times \mathrm{SL}$ & 1,23 & $<1$ & 27.76 & .702 & .006 \\
\hline
\end{tabular}

scores to a 2 (Stimulus Type: word vs. nonword) $\times 2$ (Keyboard Type: regular vs. laser) ANOVA, and found a significant main effect of Keyboard Type, $F(1,19)=32.60, M S E=28,659, p<$ $.001, \eta_{p}^{2}=.632 . \mathrm{E}+2$ keystroke was faster than $\mathrm{E}+1$ keystroke by $249 \mathrm{~ms}(S E=44)$ for the regular keyboard, whereas it was faster only by $33 \mathrm{~ms}(S E=32)$ for the laser keyboard, indicating greater persistence of posterror slowing for the laser keyboard. This suggests a prevention motive for posterror slowing with the regular keyboard and a cure motive for posterror slowing with the regular keyboard (Crump \& Logan, in press).

\section{Discussion}

Experiment 3 found that the laser keyboard disrupted skilled typing substantially, increasing both RT and IKSI, and it also affected the magnitude and persistence of posterror slowing, indicating that altering haptic feedback changed the way typists reacted to errors (Crump \& Logan, in press). There was little evidence that disabling associations between keys and finger movements affected hierarchical control. RT and IKSI were shorter for words than for nonwords with both keyboards. Moreover, the string length effect was smaller for words than for nonwords with both keyboards, and the string length effect did not differ between the regular and laser keyboards when typing words. These results suggest that altering haptic feedback did not increase the number of motor chunks for words, implying that keystrokes were programmed in the inner loop for both keyboards. The analysis of posterror slowing also appears to agree with this conclusion. Although the smaller magnitude of posterror slowing for the laser keyboard could reflect a greater "cognitive slack" with the laser keyboard that absorbed a larger portion of the slowing, the persistence of the slowing after an error keystroke could reflect the possibility that the outer loop took control of keystrokes away from the inner loop after an error. This would imply that the inner loop still controls keystrokes before an error. More broadly, the results suggest that altering haptic feedback did not force the outer loop to control the execution of each keystroke. Instead, it required the outer loop to monitor keystrokes, slowing the inner loop but still allowing it to prepare and execute the usual motor chunks.

\section{Experiment 4}

Experiment 4 disabled associations between keys and finger movements to examine their effects on chunking in STM. Experiment 2 dissociated chunking in motor planning from chunking in 


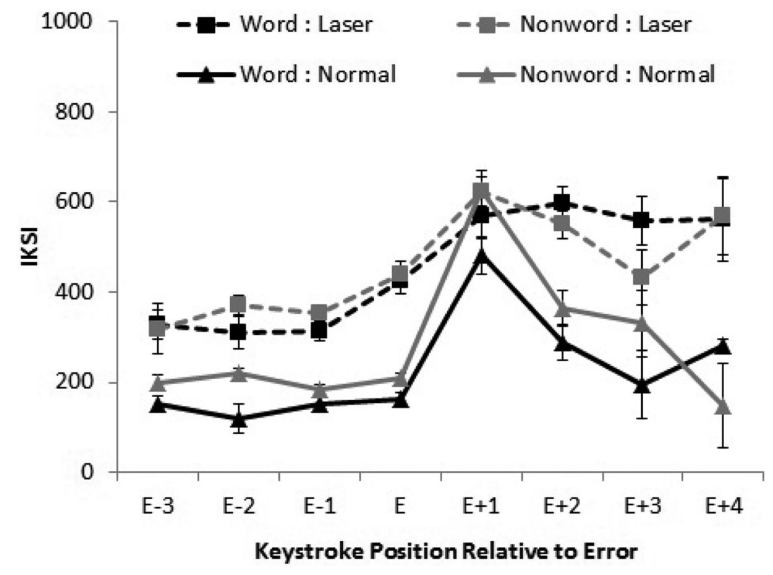

Figure 7. Interkeystroke interval (IKSI) for error trials as a keystroke position relative to the first error keystroke $(\mathrm{E}=$ error keystroke; $\mathrm{E}-n=$ $n$ keystrokes before the error; $\mathrm{E}+n=n$ keystrokes after the error: error bars represent standard errors of the means).

STM. Retrieval of motor chunks occurs in the interface between the outer loop and the inner loop, whereas short-term retention of words and letters occurs in the outer loop (Logan \& Crump, 2011). Thus, we might expect no effect of disabling motor associations on chunking in STM. Words would be represented as single chunks, so short-term retention should not be affected by word length. However, as Experiment 3 suggests, altering haptic feedback forces the outer loop to monitor keystrokes, so chunking in STM may be disrupted. Thus, words would be represented as several chunks, and short-term retention should be worse for longer words than for shorter words.

Experiment 4 was similar to Experiment 2, except that typists typed with the regular and laser keyboards while performing a concurrent memory task. We used only words and assessed whether chunking in STM was disrupted by typing on the laser keyboard by looking at the effect of word length on memory performance.

\section{Method}

Subjects. Twenty-four touch typists were newly recruited from the Vanderbilt University community. They were paid $\$ 12$ for participation. All typists typed with the conventional finger placements on the QWERTY keyboard. The mean typing speed and accuracy in the typing test were 81.71 WPM $(S D=1.77)$ and $94.16 \%(S D=0.41)$, respectively. These typists reported having 4.80 months $(S D=0.71)$ of formal training and 11.42 years $(S D=$ $0.67)$ of typing experience, and spending 4.25 hours per day $(S D=$ 0.37 ) in front of computer.

Apparatus, stimuli, and procedure. The apparatus was identical with that used in Experiment 2, except that there were two types of keyboard, the regular keyboard and the laser keyboard used in Experiment 3. Stimuli were words also used in Experiment 2 , and the procedure followed that experiment as well.

Each typist performed two separate phases with the two keyboard types. Each phase consisted of two blocks of eight practice trials (one with low memory load and one with high memory load) and four blocks of 44 test trials (two blocks for each memory load).
Half the typists had the low memory load condition in the first and third test blocks and the high memory load condition in the second and fourth blocks; the other half had the high memory load condition in the first and third blocks and the low memory load condition in the second and fourth blocks. The timing in each trial was also identical with the timing in Experiment 2, except that the go signal remained on the screen for $5,000 \mathrm{~ms}$ or until typists made as many keystrokes as the number of letters in the to-be-typed word (in Experiment 2, the interval was fixed at 3,000 ms). This modification was made due to the slower typing rate with the laser keyboard. In addition, because the laser keyboard was not equipped with a numeric keypad, a separate numeric keypad was placed on the location roughly the same as the position of the number pad equipped on the regular keyboard.

\section{Results}

The data were analyzed in the same manner as in Experiment 2. $\mathrm{PE}_{\text {recall }}$, RT, IKSI, and $\mathrm{PE}_{\text {typing }}$ are plotted in Figure 8. They were submitted to 2 (Keyboard Type: regular vs. laser) $\times 2$ (Word Length: 3 letter vs. 5 letter) $\times 2$ (Memory Load: high vs. low) ANOVAs. The results are summarized in Table 4. As in the preceding experiments, differences discussed below are significant in the ANOVAs unless noted otherwise.

Chunking in STM. We expected that $\mathrm{PE}_{\text {recall }}$ would be affected by word length for the laser keyboard if altering haptic feedback increased the number of chunks in STM. The results showed little effect of word length, indicating that the laser keyboard did not affect chunking in STM.

$\mathrm{PE}_{\text {recall }}$ was larger for the laser keyboard $(M=10.00 \% ; S E=$ 1.18) than for the regular keyboard $(M=8.17 \% ; S E=1.15)$, but there was little evidence that the laser keyboard altered hierarchical control. $\mathrm{PE}_{\text {recall }}$ was generally larger for 5-letter words than for 3-letter words, but this word length effect was not modulated by keyboard type. Also, $\mathrm{PE}_{\text {recall }}$ increased with memory load $(\mathrm{Ms}=$ $2.35 \%$ and $15.82 \%$ for low and high loads, respectively; SEs = 0.28 and 2.01), but the memory load effect was not modulated by keyboard type either.

There was an interaction between memory load and word length, reflecting a larger word length effect in the high load condition $(M \mathrm{~s}=13.07 \%$ and 18.56 for 3 - and 5-letter words, respectively; $S E \mathrm{~s}=1.71$ and 2.39 ) than in the low load condition $(M \mathrm{~s}=1.61 \%$ and $3.10 \% ; S E \mathrm{~s}=0.32$ and 0.48$)$. The interaction may reflect the possibility that longer words exceed STM capacity more than shorter words when memory load is high. This outcome is consistent with Experiment 2.

Chunking in motor planning. We assessed chunking in motor planning by examining the word length effect in RT. Experiment 3 suggested that altering haptic feedback did not increase the number of motor chunks, so we expected that the word length effect would be the same for the two types of keyboard. The results confirmed the prediction.

RT was generally longer with the laser keyboard $(M=720 \mathrm{~ms}$; $S E=35)$ than with the regular keyboard $(M=510 \mathrm{~ms} ; S E=26)$. RT did not depend on word length, consistent with Experiment 3 and suggesting that the number of motor chunks did not increase with the laser keyboard. RT increased for high memory load and the increase was larger for the laser keyboard $(M=256 \mathrm{~ms} ; S E=$ $33)$ than for the regular keyboard $(M=142 \mathrm{~ms} ; S E=22)$. 

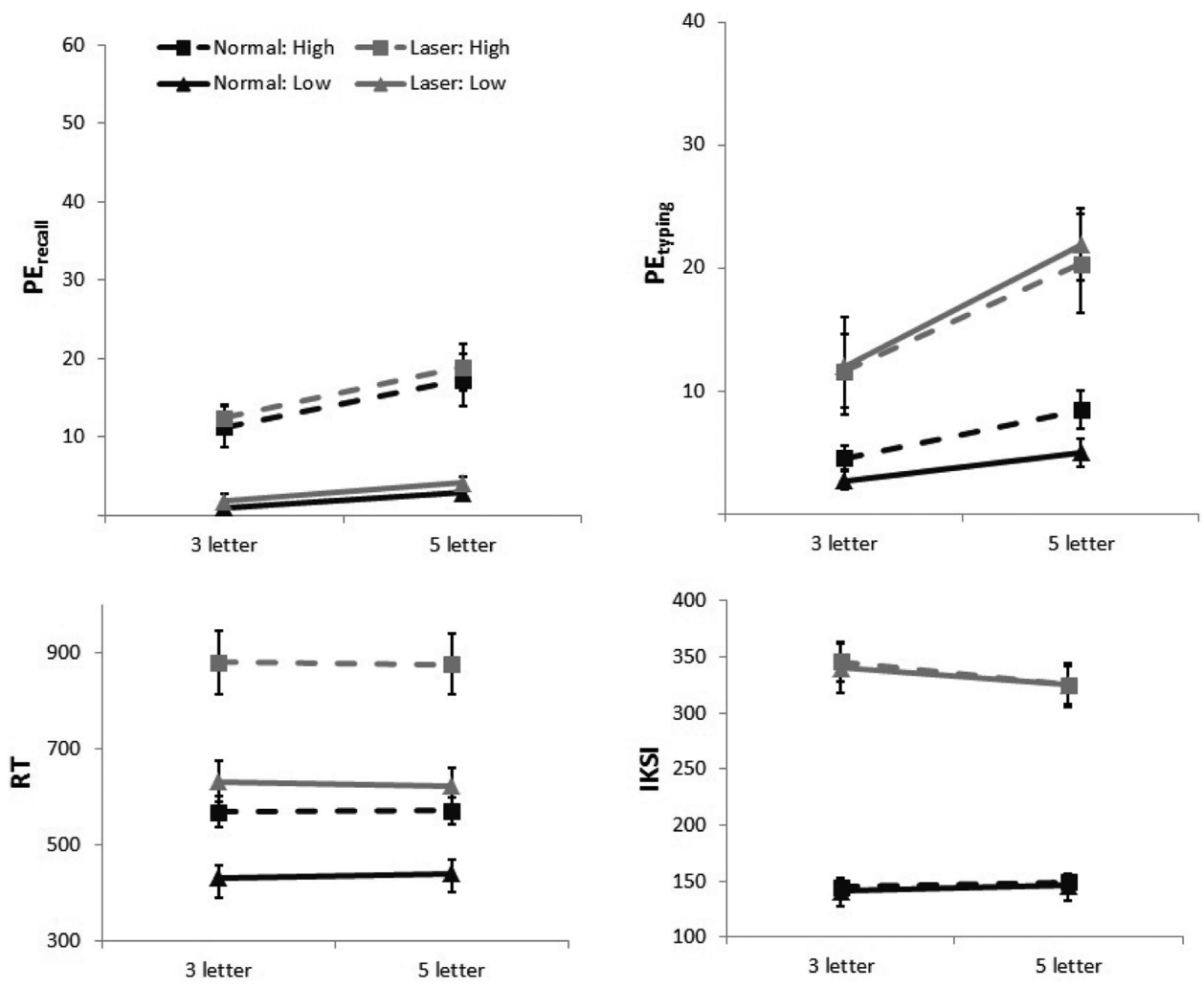

Figure 8. Mean percentage errors in recall $\left(\mathrm{PE}_{\text {recall }}\right)$, percentage errors in typing $\left(\mathrm{PE}_{\text {typing }}\right)$, response times (RT), and interkeystroke interval (IKSI) in Experiment 4 (error bars represent standard errors of the means).

IKSI was also longer with the laser keyboard $(M=231 \mathrm{~ms} ; S E=$ $13)$ than with the regular keyboard $(M=146 \mathrm{~ms} ; S E=6)$. IKSI was not affected by memory load. IKSI showed different patterns of word length for the two keyboards: With the regular keyboard, the word length effect was $3 \mathrm{~ms} / \mathrm{letter}(S E=1)$; with the laser keyboard, the word length effect was $-11 \mathrm{~ms} / \mathrm{letter}(S E=3)$. The reason for the decreasing word length effect with the laser keyboard is not clear. It is unlikely that the laser keyboard reduced the number of motor chunks for longer words, so the result may simply be due to chance. The important point is that there was little evidence indicating that the number of motor chunks increased for the laser keyboard.

$\mathrm{PE}_{\text {typing }}$ was larger for the laser keyboard $(M=15.11 \%$; $S E=$ 1.78) than for the regular keyboard $(M=5.03 \% ; S E=5.03)$, and it was also larger for longer words $(M=13.36 \% ; S E=1.11)$ than for shorter words $(M=6.78 \% ; S E=0.96)$. The effect of word length was larger with the laser keyboard $(M \mathrm{~s}=10.42 \%$ vs. $19.80 \%$ for 3and 5-letter words; $S E$ s $=1.88$ and 1.92) than with the regular keyboard $(M \mathrm{~s}=3.14 \%$ vs. $6.92 \%$ for 3 - and 5-letter words; $S E \mathrm{~s}=$ 0.52 and 0.88$)$.

\section{Discussion}

The present experiment provided little evidence that disabling associations between keys and finger movements alters chunking in STM. Although recall errors increased somewhat with the laser keyboard, the word length effect was the same with both keyboards, suggesting that monitoring keystrokes did not affect the units of STM. Consistent with Experiment 3, the laser keyboard did not increase the word length effect in RT, supporting the conclusion that disabling associations between keys and finger movements did not affect chunking in motor planning.

\section{General Discussion}

Hierarchical control enables rapid implementation of complex skills by allowing multiple component processes to operate concurrently. Chunking plays a critical role in enabling concurrent processing (e.g., Bryan \& Harter, 1899; Lashley, 1951; Rhodes et al., 2004; Sternberg et al., 1978). Chunking develops over practice, so we can study it by comparing skilled and unskilled performance. To do so, we pushed skilled typists back on the learning curve by degrading two out of three types of associations that support skilled typewriting: associations between words and keys, and associations between keys and finger movements (we did not degrade associations between letters and keys). We examined contributions of these associations to chunking in three different processes underlying skilled typing.

Experiments 1 and 2 examined the contribution of associations between words and letters by scrambling the order of letters in words. Experiment 1 demonstrated that scrambling word order altered units of encoding. When typing words, stimulus noise increased RT, but it did not influence IKSI, indicating that encoding occurred once for each word before the first keystroke. When typing nonwords, stimulus noise increased RT and IKSI, indicating that encoding occurred after the first keystroke is initiated. Thus, skilled typewriting involves chunking in perception. Experiment 2 demonstrated that scrambling word order altered units of STM. In the concurrent memory task, 
Table 4

ANOVA Results for Percent Recall Errors $\left(P E_{\text {Recall }}\right)$, Response Times $(R T)$, Interkeystroke Interval (IKSI), and Percent Typing Errors $\left(P E_{\text {Typing }}\right)$ in Experiment 4

\begin{tabular}{|c|c|c|c|c|c|}
\hline Factor & $d f$ & $F$ & $M S E$ & $p$ & $\eta_{p}^{2}$ \\
\hline & & & $\mathrm{RT}$ & & \\
\hline Keyboard Type (KT) & 1,23 & 291.78 & 26,704 & $<.001$ & .927 \\
\hline Stimulus Type (ST) & 1,23 & 152.19 & 5,938 & $<.001$ & .869 \\
\hline String Length (SL) & 2,46 & 45.4 & 1,511 & $<.001$ & .664 \\
\hline $\mathrm{KT} \times \mathrm{ST}$ & 1,23 & $<1$ & 2,077 & .666 & .008 \\
\hline $\mathrm{KT} \times \mathrm{SL}$ & 2,46 & 6.32 & 1,435 & .004 & .216 \\
\hline $\mathrm{ST} \times \mathrm{SL}$ & 2,46 & 16.71 & 1,090 & $<.001$ & .421 \\
\hline \multirow[t]{2}{*}{$\mathrm{KT} \times \mathrm{ST} \times \mathrm{SL}$} & 2,46 & 4.40 & 1,169 & .018 & .160 \\
\hline & & & IKSI & & \\
\hline KT & 1,23 & 176.11 & 21,185 & $<.001$ & .884 \\
\hline ST & 1,23 & 77.32 & 1,460 & $<.001$ & .771 \\
\hline SL & 2,46 & 25.03 & 487 & $<.001$ & .521 \\
\hline $\mathrm{KT} \times \mathrm{ST}$ & 1,23 & 5.22 & 568 & .032 & .185 \\
\hline $\mathrm{KT} \times \mathrm{SL}$ & 2,46 & $<1$ & 384 & .718 & .014 \\
\hline $\mathrm{ST} \times \mathrm{SL}$ & 2,46 & 48.82 & 261 & $<.001$ & .680 \\
\hline \multirow[t]{2}{*}{$\mathrm{KT} \times \mathrm{ST} \times \mathrm{SL}$} & 2,46 & 11.27 & 336 & $<.001$ & .329 \\
\hline & & & PE & & \\
\hline KT & 1,23 & 44.51 & 197.04 & $<.001$ & .659 \\
\hline ST & 1,23 & 2.90 & 34.42 & .102 & .112 \\
\hline SL & 2,46 & 41.06 & 20.57 & $<.001$ & .641 \\
\hline $\mathrm{KT} \times \mathrm{ST}$ & 1,23 & 5.63 & 30.26 & .026 & .197 \\
\hline $\mathrm{KT} \times \mathrm{SL}$ & 2,46 & 7.17 & 34.48 & .002 & .238 \\
\hline $\mathrm{ST} \times \mathrm{SL}$ & 2,46 & $<1$ & 24.19 & .856 & .007 \\
\hline $\mathrm{KT} \times \mathrm{ST} \times \mathrm{SL}$ & 2,46 & $<1$ & 18.56 & .473 & .032 \\
\hline
\end{tabular}

performance was not affected much by the number of letters in words, but was greatly disrupted by the number of letters in nonwords. Thus, skilled typewriting involves chunking in STM. Furthermore, both experiments demonstrated that scrambling word order altered units of motor planning. RT increased as the number of letters in nonwords increased, and this increase was much larger than the increase as the number of letters in words increased. Thus, skilled typewriting involves chunking in motor planning. This chunking in motor planning was dissociated from chunking in perception in Experiment 1 and from chunking in STM in Experiment 2.

Experiments 3 and 4 examined contributions of associations between keys and finger movements by altering haptic feedback to the fingers. Experiment 3 demonstrated that altering haptic feedback slowed typing, but typing words was still faster than typing nonwords. Also, string length increases RT when typing words with the laser keyboard no more than when typing words with the regular keyboard. Thus, altering haptic feedback did not alter chunking in motor planning. Experiment 4 demonstrated that word length affected concurrent memory performance to the similar extent with the two types of keyboard. Thus, altering haptic feedback did not alter chunking in STM. We discuss implications of these results about the role of automatic processes in hierarchical control of skilled performance.

\section{The Role of Automaticity in Hierarchical Control of Skill}

Automatization of component processes precedes the development of hierarchical control (e.g., Abrahamse et al., 2013; Bryan \& Harter, 1899; LaBerge \& Samuels, 1974; Rhodes et al., 2004; Vallacher \& Wegner, 1987). Automaticity develops by strengthening the associations that underlie the skill, and hierarchical processing emerges when the associations become strong enough to support performance without conscious control (LaBerge \& Samuels, 1974; Logan, 1988; Schneider \& Shiffrin, 1977). Hierarchical control involves executing different levels of processing in parallel, and there are strict limits on the ability to perform cognitive processes in parallel (Pashler, 1998; Welford, 1952). Thus, automaticity seems to be necessary to execute component processes in parallel (e.g., Greenwald \& Shulman, 1973; Hazeltine, Teague, \& Ivry, 2002; Maquestiaux, Laguë-Beauvais, Ruthruff, \& Bherer, 2008; Schumacher, Seymour, Glass, Kieras, \& Meyer, 2001; Shaffer, 1975b).

As stated previously, we proposed that skilled typing depends on automatizing three types of association: associations between words and letters, associations between letters and keys, and associations between keys and finger movements. Associations between words and letters automatize retrieval of individual letters, so typists do not have to attend each letter they type; associations between letters and keys automatize retrieval of keystroke schemata, so typists do not have to attend to the translation of individual letters to the corresponding keystrokes; and associations between keys and fingers automatize implementation of keystrokes, so typists do not have to attend to each keystroke. In the present study, we examined the role of associations between words and letters and associations between keys and fingers in enabling hierarchical control of skilled typewriting, and showed that the former are critical in enabling hierarchical control but latter are not.

Associations between words and letters enable hierarchical control by supporting chunking. Through associative learning, a single word becomes associated with each of the letters that comprise it, producing a one-to-many mapping that is characteristic of hierarchical control 
(Logan \& Crump, 2011; Miller et al., 1960). Chunking benefits touch typing because it compresses data (Chase \& Simon, 1973; Klapp, 1995) and allows higher- and lower-level processes to operate in parallel (Rhodes et al., 2004). This reduces cognitive load and increases the speed of processing (De Kleine \& van der Lubbe, 2011). Chunking increases distinctiveness of memory representations, and distinctiveness increases as the size of chunks increase (Newell \& Rosenbloom, 1981). This reduces interference when retrieving the relevant chunk and increases the accuracy of performance.

The associations between keys and fingers are not necessary for chunking in skilled typewriting. We were surprised to find that haptic feedback did not disable hierarchical control because the inner loop depends on haptic feedback from the keyboard (Crump \& Logan, 2010c; Gordon \& Soechting, 1995). Our results suggest that altering haptic feedback compromised the inner loop's ability to monitor keystrokes, so that the outer loop had to take over. Thus, motor chunks remained intact, but keystrokes were slowed to allow the outer loop to monitor them (Logan \& Crump, 2009; Snyder \& Logan, in press). Our analysis of posterror slowing in Experiment 3 supports this conclusion. For the regular keyboard, posterror slowing was strong but dissipated quickly after an error, indicating suppression of an automatic tendency to correct the error (Crump \& Logan, in press). For the laser keyboard, posterror slowing dissipated slowly after an error, indicating a strategic adjustment that was intended to prevent further errors (Crump \& Logan, in press). The sustained pattern with the laser keyboard reflects the involvement of the outer loop in monitoring keystroke errors. One of our ongoing projects tested and confirmed the involvement of the outer loop in monitoring keystrokes with the laser keyboard. We have not yet published those results and will, therefore, not discuss them further.

The present study did not examine the role of associations between letters and keys for skilled typewriting. These associations support another component of the inner loop control that remained intact in the present study: the selection of keystrokes for each letter. We suggest that these associations might support motor chunking. Future studies are needed to address the role of letterkey associations in skilled typewriting.

\section{On the Constituents of Chunks in Skilled Typing}

The present study provided several indications of chunking in skilled typing that depended on the typing material. There was a clear advantage of words over nonwords, suggesting that chunking differed between materials, but the results do not reveal the constituents of chunking. The nonwords we used scrambled the order of letters in words, and that destroys sequential dependencies between letters and positional frequencies of letters as well as the meaningful form of words. Thus, we cannot distinguish between several possible constituents of chunks in skilled typing, such as syllables, morphemes, and digraphs. Previous studies have indicated that some of these constituents contribute to typing performance (e.g., Fendrick, 1937; Gentner et al., 1988; Inhoff, 1991; Shaffer \& Hardwick, 1970; West \& Sabban, 1982), but these studies do not indicate the level of processing at which these factors affect typing.

Logan and Crump (2011) assumed that words are single chunks in the outer loop. However, we found that typing words sometimes produced a string length effect, which suggests that the number of motor chunks may be larger for longer words than for shorter words or larger for unfamiliar words than for familiar ones. Also, the string length effect for words may be due to the size of the motor chunks rather than the number of motor chunks (Klapp, 1995; Wright et al., 2004).

We found a string length effect in IKSI for nonwords (also see Sternberg et al., 1978; Verwey, 1996; Verwey \& Eikelboom, 2003; Rhodes et al., 2004), which bears on the nature of chunking in nonwords. The string-length effect may reflect increased time in retrieving motor chunks from a buffer (Sternberg et al., 1978) or the segmentation of an unfamiliar sequence into multiple groups (e.g., Verwey, 2003; Verwey \& Eikelboom, 2003). In either case, typing nonwords may involve units that are intermediate between single words and single letters (e.g., syllables, digraphs, etc.). This possibility is left for future investigations.

\section{Concluding Remarks}

In the present study, we considered three types of association that support skilled typewriting and manipulated two types: associations between words and letters, and associations between keys and finger movements. We disabled associations between words and letters by scrambling letter orders, and found that is critical in chunking in perception, STM, and motor planning. Thus, typing familiar words is special, compared with typing unfamiliar nonwords. We also disabled associations between keys and finger movements by altering the haptic feedback that the inner loop relies on by using the laser keyboard. Typing was much slower and less accurate with the laser keyboard, but altering haptic feedback did not disable chunking in any of the three processes. These results suggest that associations between words and letters underlie skilled typing and support hierarchical control, whereas associations between keys and finger movements are not important for hierarchical control. Future research will reveal whether the third type of association, that between letters and keys, contributes to the hierarchical control of skilled typewriting.

\section{References}

Abrahamse, E. L., Ruitenberg, M. F., de Kleine, E., \& Verwey, W. B. (2013). Control of automated behavior: Insights from the discrete sequence production task. Frontiers in Human Neuroscience, 7, 82. doi: 10.3389/fnhum.2013.00082

Barrouillet, P., \& Camos, V. (2012). As time goes by: Temporal constraints in working memory. Current Directions in Psychological Science, 21, 413-419. doi:10.1177/0963721412459513

Botvinick, M., \& Plaut, D. C. (2004). Doing without schema hierarchy: A recurrent connectionist approach to routine sequential action and its pathologies. Psychological Review, 111, 395-429. doi:10.1037/0033295X.111.2.395

Bryan, W. L., \& Harter, S. N. (1899). Studies on the telegraphic language: The acquisition of a hierarchy of habits. Psychological Review, 6, 345-375. doi:10.1037/h0073117

Butsch, R. L. C. (1932). Eye movements and the eye-hand span in typewriting. Journal of Educational Psychology, 23, 104-121. doi:10.1037/ h0073463

Chase, W. G., \& Simon, H. A. (1973). Perception in chess. Cognitive Psychology, 4, 55-81. doi:10.1016/0010-0285(73)90004-2

Coltheart, M. (1981). The MRC psycholinguistic database. Quarterly Journal of Experimental Psychology, 33A, 497-505.

Cooper, R. P., \& Shallice, T. (2000). Contention scheduling and the control of routine activities. Cognitive Psychology, 17, 297-338. 
Cooper, R. P., \& Shallice, T. (2006). Hierarchical schemas and goals in the control of behavior. Psychological Review, 113, 887-916. doi:10.1037/ 0033-295X.113.4.887

Cowan, N. (2001). The magical number 4 in short-term memory: A reconsideration of mental storage capacity. Behavioral and Brain Sciences, 24, 87-114. doi:10.1017/S0140525X01003922

Crump, M. J. C., \& Logan, G. D. (2010a). Episodic contributions to sequential control: Learning from a typist's touch. Journal of Experimental Psychology: Human Perception and Performance, 36, 662-672. doi: $10.1037 / \mathrm{a} 0018390$

Crump, M. J. C., \& Logan, G. D. (2010b). Hierarchical control and skilled typing: Evidence for word-level control over the execution of individual keystrokes. Journal of Experimental Psychology: Learning, Memory, and Cognition, 36, 1369-1380. doi:10.1037/a0020696

Crump, M. J. C., \& Logan, G. D. (2010c). Warning: This keyboard will deconstruct-The role of the keyboard in skilled typewriting. Psychonomic Bulletin \& Review, 17, 394-399. doi:10.3758/PBR.17.3.394

Crump, M. J. C., \& Logan, G. D. (in press). Prevention and correction in post-error performance: An ounce of prevention, a pound of cure. Journal of Experimental Psychology: General.

De Kleine, E., \& van der Lubbe, R. H. J. (2011). Decreased load on general motor preparation and visual-working memory while preparing familiar as compared to unfamiliar movement sequences. Brain and Cognition, 75, 126-134. doi:10.1016/j.bandc.2010.10.013

Diehl, M. J., \& Seibel, R. (1962). The relative importance of visual and auditory feedback in skilled typewriting. Journal of Applied Psychology, 46, 365-369. doi:10.1037/h0041438

Elman, J. L. (1990). Finding structure in time. Cognitive Science, 14, 179-211. doi:10.1207/s15516709cog1402_1

Fendrick, P. (1937). Hierarchical skills in typewriting. Journal of Educational Psychology, 28, 609-620. doi:10.1037/h0054049

Fitts, P. M., \& Posner, M. I. (1967). Human performance. Belmont, CA: Brooks/Cole.

FitzGerald, P., Tattersall, A., \& Broadbent, D. (1988). Separating central mechanisms by POCs: Evidence for an input-output buffer. Quarterly Journal of Experimental Psychology, 40, 109-134.

Gentner, D. R., Larochelle, S., \& Grudin, J. (1988). Lexical, sublexical, and peripheral effects in skilled typewriting. Cognitive Psychology, 20, 524-548. doi:10.1016/0010-0285(88)90015-1

Gordon, A. M., \& Soechting, J. F. (1995). Use of tactile afferent information in sequential finger movements. Experimental Brain Research, 107, 281-292. doi:10.1007/BF00230048

Greenwald, A. G., \& Shulman, H. (1973). On doing two things at once: II. Elimination of the psychological refractory period. Journal of Experimental Psychology, 101, 70-76. doi:10.1037/h0035451

Hazeltine, E., Teague, D., \& Ivry, R. B. (2002). Simultaneous dual-task performance reveals parallel response selection after practice. Journal of Experimental Psychology: Human Perception and Performance, 28, 527-545. doi:10.1037/0096-1523.28.3.527

Henry, F. M., \& Rogers, E. E. (1960). Increased response latency for complicated movements and a "memory drum" theory of neuromotor reaction. Research Quarterly of the American Association of Health, 31, $448-458$.

Inhoff, A. W. (1991). Word frequency during copytyping. Journal of Experimental Psychology: Human Perception and Performance, 17, 478-487. doi:10.1037/0096-1523.17.2.478

Keele, S., \& Posner, M. (1968). Processing of visual information in rapid movements. Journal of Experimental Psychology, 77, 155-158. doi: $10.1037 / \mathrm{h} 0025754$

Klapp, S. T. (1995). Motor response programming during simple and choice reaction time: The role of practice. Journal of Experimental Psychology: Human Perception and Performance, 21, 1015-1027. doi: 10.1037/0096-1523.21.5.1015
Klapp, S. T., Abbott, J., Coffman, K., Greim, D., Snider, R., \& Young, F. (1979). Simple and choice reaction time methods in the study of motor programming. Journal of Motor Behavior, 11, 91-101.

LaBerge, D., \& Samuels, S. J. (1974). Toward a theory of automatic information processing in reading. Cognitive Psychology, 6, 293-323. doi:10.1016/0010-0285(74)90015-2

Lashley, K. S. (1951). The problem of serial order in behavior. In L. A Jeffress (Ed.), Cerebral mechanisms in behavior (pp. 112-146). New York, NY: Wiley.

Leonard, J. A., \& Newman, R. C. (1964). Formation of higher habits. Nature, 203, 550-551. doi:10.1038/203550b0

Liu, X., Crump, M. J. C., \& Logan, G. D. (2010). Do you know where your fingers have been? Explicit knowledge of the spatial layout of the keyboard in skilled typists. Memory \& Cognition, 38, 474-484. doi 10.3758/MC.38.4.474

Logan, G. D. (1988). Toward an instance theory of automatization. Psychological Review, 95, 492-527. doi:10.1037/0033-295X.95.4.492

Logan, G. D. (2003). Simon-type effects: Chronometric evidence for keypress schemata in typewriting. Journal of Experimental Psychology: Human Perception and Performance, 29, 741-757.

Logan, G. D., \& Crump, M. J. C. (2009). The left hand doesn't know what the right hand is doing: The disruptive effects of attention to the hands in skilled typewriting. Psychological Science, 20, 1296-1300.

Logan, G. D., \& Crump, M. J. C. (2010). Cognitive illusions of authorship reveal hierarchical error detection in skilled typists. Science, 330, $683-$ 686. doi:10.1126/science. 1190483

Logan, G. D., \& Crump, M. J. C. (2011). Hierarchical control of cognitive processes: The case for skilled typewriting. In B. Ross (Ed.), The psychology of learning and motivation (Vol. 54, pp. 1-27). Burlington, MA: Academic Press.

Logan, G. D., Miller, A. E., \& Strayer, D. L. (2011). Electrophysiological evidence for parallel response selection in skilled typists. Psychological Science, 22, 54-56. doi:10.1177/0956797610390382

Logan, G. D., \& Zbrodoff, N. J. (1998). Stroop-type interference: Congruity effects in color naming with typewritten responses. Journal of Experimental Psychology: Human Perception and Performance, 24, 978 992. doi: $10.1037 / 0096-1523.24 .3 .978$

MacKay, D. G. (1982). The problem of flexibility, fluency, and speedaccuracy tradeoff in skilled behavior. Psychological Review, 89, 483506. doi:10.1037/0033-295X.89.5.483

Magill, R. A. (2007). Motor learning and control (8th ed.). New York, NY: McGraw-Hill

Maquestiaux, F., Laguë-Beauvais, M., Ruthruff, E., \& Bherer, L. (2008). Bypassing the central bottleneck after single-task practice in the psychological refractory period paradigm: Evidence for task automatization and greedy resource recruitment. Memory \& Cognition, 36, 1262-1282. doi:10.3758/MC.36.7.1262

McClelland, J. L., \& Johnston, J. C. (1977). The role of familiar units in perception of words and nonwords. Perception \& Psychophysics, 22, 249-261. doi:10.3758/BF03199687

McClelland, J. L., \& Rumelhart, D. E. (1981). An interactive activation model of context effects in letter perception: Pt. 1. An account of basic findings. Psychological Review, 88, 375-407. doi:10.1037/0033-295X 88.5.375

Miller, G. A. (1956). The magical number seven, plus or minus two: Some limits on our capacity for processing information. Psychological Review, 63, 81-97. doi:10.1037/h0043158

Miller, G. A., Galanter, E., \& Pribram, K. H. (1960). Plans and the structure of behavior. New York, NY: Adams-Bannister-Cox. doi: 10.1037/10039-000

Murdock, B. B. (1961). The retention of individual items. Journal of Experimental Psychology, 62, 618-625. doi:10.1037/h0043657

Newell, A., \& Rosenbloom, P. (1981). Mechanisms of skill acquisition and 
the law of practice. In J. R. Anderson (Ed.), Cognitive skills and their acquisition (pp. 1-55). Hillsdale, NJ: Erlbaum.

Pashler, H. (1998). The psychology of attention. Cambridge, MA: MIT Press.

Pew, R. W. (1974). Human perceptual-motor performance. In B. H. Kantowitz (Ed.), Human information processing: Tutorials in performance and cognition (pp. 1-39). Hillsdale, NJ: Erlbaum.

Reicher, G. M. (1969). Perceptual recognition as a function of frequent and infrequent words. Journal of Experimental Psychology, 81, 275-280. doi: $10.1037 / \mathrm{h} 0027768$

Rhodes, B. J., Bullock, D., Verwey, W. B., Averbeck, B. B., \& Page, M. P. A. (2004). Learning and production of movement sequences: Behavioral, neurophysiological, and modeling perspectives. Human Movement Science, 23, 699-746. doi:10.1016/j.humov.2004.10.008

Rumelhart, D. E., \& Norman, D. A. (1982). Simulating a skilled typist: A study of skilled cognitive-motor performance. Cognitive Science, 6 , 1-36. doi:10.1207/s15516709 $\operatorname{cog} 0601$

Sakai, K., Kitaguchi, K., \& Hikosaka, O. (2003). Chunking during human visuomotor sequence learning. Experimental Brain Research, 152, 229 242. doi:10.1007/s00221-003-1548-8

Salmoni, A. W., Schmidt, R. A., \& Walter, C. B. (1984). Knowledge of results and motor learning: A review and critical appraisal. Psychological Bulletin, 95, 355-386. doi:10.1037/0033-2909.95.3.355

Salthouse, T. A. (1984). Effects of age and skill in typing. Journal of Experimental Psychology: General, 113, 345-371. doi:10.1037/00963445.113.3.345

Salthouse, T. A. (1986). Perceptual, cognitive, and motoric aspects of transcription typing. Psychological Bulletin, 99, 303-319. doi:10.1037/ 0033-2909.99.3.303

Schmidt, R. A., \& Lee, T. D. (2005). Motor control and learning (4th ed.). Campaign, IL: Human Kinetics.

Schneider, W., \& Shiffrin, R. M. (1977). Controlled and automatic human information processing: I. Detection, search, and attention. Psychological Review, 84, 1-66. doi:10.1037/0033-295X.84.1.1

Schumacher, E. H., Seymour, T. L., Glass, J. M., Kieras, D. E., \& Meyer, D. E. (2001). Virtually perfect time sharing in dual-task performance: Uncorking the central attentional bottleneck. Psychological Science, 12, 101-108. doi:10.1111/1467-9280.00318

Shaffer, L. H. (1973). Latency mechanisms in transcription. In S. Kornblum (Ed.), Attention and performance IV (pp. 435-448). New York, NY: Academic Press.

Shaffer, L. H. (1975a). Control processes in typing. Quarterly Journal of Experimental Psychology, 27, 419-432. doi:10.1080/ 14640747508400502

Shaffer, L. H. (1975b). Multiple attention in continuous verbal tasks. In. P. M. A. Rabbitt \& S. Dornic (Eds.), Attention and performance $V$ (pp. 157-167). New York, NY: Academic Press.

Shaffer, L. H., \& Hardwick, J. (1968). Typing performance as a function of text. Quarterly Journal of Experimental Psychology, 20, 360-369. doi:10.1080/14640746808400175

Shaffer, L. H., \& Hardwick, J. (1970). The basis of transcription skill. Journal of Experimental Psychology, 84, 424-440. doi:10.1037/ h0029287

Smyth, M. M., \& Pendleton, L. R. (1989). Working memory for movements. Quarterly Journal of Experimental Psychology, 41, 235-250.

Snyder, K. M., \& Logan, G. D. (in press). Monitoring-induced disruption in skilled typewriting. Journal of Experimental Psychology: Human Perception and Performance.
Snyder, K. M., \& Logan, G. D., \& Yamaguchi, M. (2013). Watch what you type: The role of visual feedback from the screen and hands in skilled typewriting. Manuscript submitted for publication.

Sternberg, S. (1969). The discovery of processing stages: Extensions of Donders' method. Acta Psychologica, 30, 276-315.

Sternberg, S., Monsell, S., Knoll, R. L., \& Wright, C. E. (1978). The latency and duration of speech and typewriting. In G. E. Stelmach (Ed.), Information processing in motor control and learning (pp. 117-152). New York, NY: Academic Press.

Tattersall, A. J., \& Broadbent, D. E. (1991). Output buffer storage and the modality of recall. Quarterly Journal of Experimental Psychology, 43A $1-18$.

Thomas, E. A. C., \& Jones, R. G. (1970). A model for subjective grouping in typewriting. Quarterly Journal of Experimental Psychology, 22, 353367. doi:10.1080/14640747008401907

Vallacher, R. R., \& Wegner, D. M. (1987). What do people think they're doing? Action identification and human behavior. Psychological Review, 94, 3-15. doi:10.1037/0033-295X.94.1.3

van Mier, H., \& Hulstijn, W. (1993). The effects of motor complexity and practice on initiation time in writing and drawing. Acta Psychologica, 84, 231-251. doi:10.1016/0001-6918(93)90062-V

Verwey, W. B. (1996). Buffer loading and chunking in sequential keypressing. Journal of Experimental Psychology: Human Perception and Performance, 22, 544-562.

Verwey, W. B. (1999). Evidence for a multistage model of practice in a sequential movement task. Journal of Experimental Psychology: Human Perception and Performance, 25, 1693-1708. doi:10.1037/0096-1523 25.6.1693

Verwey, W. B. (2001). Concatenating familiar movement sequences: The Versatile cognitive processor. Acta Psychologica, 106, 69-95. doi: 10.1016/S0001-6918(00)00027-5

Verwey, W. B. (2003). Effect of sequence length on the execution of familiar keying sequences: Lasting segmentation and preparation? Journal of Motor Behavior, 35, 343-354. doi:10.1080/00222890309603155

Verwey, W. B., \& Eikelboom, T. (2003). Evidence for lasting sequence segmentation in the discrete sequence-production task. Journal of Motor Behavior, 35, 171-181. doi:10.1080/00222890309602131

Welford, A. T. (1952). The "psychological refractory period" and the timing of high speed performance-A review and a theory. British Journal of Psychology, 43, 2-19.

West, L. J., \& Sabban, Y. (1982). Hierarchy of stroking habits at the typewriting. Journal of Applied Psychology, 67, 370-376. doi:10.1037/ 0021-9010.67.3.370

Wright, D. L., Black, C. B., Immink, M. A., Brueckner, S., \& Magnuson C. (2004). Long-term motor programming improvements occur via concatenation of movement sequences during random but not during blocked practice. Journal of Motor Behavior, 36, 39-50. doi:10.3200/ JMBR.36.1.39-50

Yamaguchi, M., Crump, M. J. C., \& Logan, G. D. (2013). Speed-accuracy tradeoff in skilled typewriting: Decomposing the contributions of hierarchical control loops. Journal of Experimental Psychology: Human Perception and Performance, 39, 678-699. doi:10.1037/a0030512

Yamaguchi, M., Logan, G. D., \& Li, V. (in press). Multiple bottlenecks in hierarchical control of action sequences: What does "response selection" select in skilled typewriting? Journal of Experimental Psychology: $\mathrm{Hu}$ man Perception and Performance. 
Appendix A

Word and Nonword Lists Used in the Present Study

Table A1

Word Stimuli Used in Experiments 1-4

\begin{tabular}{|c|c|c|c|c|c|c|c|c|c|}
\hline \multicolumn{10}{|c|}{3 Letters } \\
\hline ACT & BED & CUP & FAN & GYM & JOG & MUD & PEW & RYE & TIN \\
\hline AGE & BEG & CUT & FAR & HAM & JOY & MUG & PIE & SAD & TIP \\
\hline AID & BET & DAD & FAT & HAT & JUG & NET & PIG & SAP & TOE \\
\hline AIM & BID & DAY & FEE & HAY & KEY & NEW & PIN & SEA & TON \\
\hline AIR & BIG & DIE & FEW & HEN & KID & NOD & PIT & SEE & TOP \\
\hline ALE & BIN & DIM & FIR & HOG & LAP & NOW & POT & SEX & TOW \\
\hline ANT & BIT & DIP & FLY & HOP & LAW & NUN & PUP & SIN & TOY \\
\hline APE & BOW & DOG & FOE & HOT & LAX & OAK & PUT & SIT & TRY \\
\hline ARC & BOX & DOT & FOG & HUE & LAY & OAT & RAP & SKI & TWO \\
\hline ARK & BOY & DRY & FOX & HUT & LED & OFF & RAT & SKY & URN \\
\hline ARM & BRA & DYE & FUN & ICE & LEG & OIL & RAW & SOB & VAN \\
\hline ART & BUD & EAR & FUR & INK & LIE & OLD & RAY & SON & VET \\
\hline ASH & BUY & EAT & GAS & INN & LIP & OUT & RED & SUE & VOW \\
\hline AXE & CAN & EEL & GEM & ION & LOG & OWL & RIB & SUM & WAR \\
\hline AYE & CAP & EGG & GET & IVY & MAD & PAN & RIM & SUN & WAX \\
\hline BAD & CAR & EGO & GIG & JAM & MAN & PAT & $\mathrm{ROB}$ & TAP & WAY \\
\hline BAG & CAT & ELF & GIN & JAR & MAP & PEA & ROD & TAR & WEB \\
\hline BAR & COW & ELM & GOD & JAW & MAT & PEG & ROE & TAX & WET \\
\hline BAT & CRY & END & GUN & JET & MAY & PEN & RUG & TEA & WIG \\
\hline BAY & CUE & EYE & GUY & JOB & MOP & PET & RUM & TIE & WIN \\
\hline \multicolumn{10}{|c|}{4 Letters $^{a}$} \\
\hline ABLE & CAMP & DEAR & FILM & HAZE & LAMB & ONCE & SCUD & TAKE & USER \\
\hline AREA & CANE & DEEP & FISH & HELD & LAST & PART & SEAT & TALK & VARY \\
\hline AURA & CART & DEFT & FIST & HELP & LESS & PATH & SECT & TAME & VEIN \\
\hline BABE & CELL & DISC & FOLD & HERO & LIVE & PECK & SEEK & TAPE & VINE \\
\hline BALD & CHEF & DISK & FOOL & HIDE & LOCK & PICK & SEND & TAXI & WAIT \\
\hline BALL & CHEW & DOES & FOUL & HILL & LOOT & PILL & SHOE & THEM & WARE \\
\hline BARE & CLAD & DONE & FRAY & HINT & LUCK & POEM & SIZE & THUD & WEAR \\
\hline BEAM & CLAN & DOOM & GAIN & HOLD & LULL & POND & SLID & TIDE & WERE \\
\hline BELT & CLUE & DRIP & GALE & HOUR & MEAT & PREY & SLIM & TILT & WHOM \\
\hline BITE & COIN & DROP & GALL & IRIS & MEET & PUNK & SLIP & TIRE & WILD \\
\hline BOLD & COST & DUCT & GASH & IRON & MERE & PUTT & SNOW & TOIL & WINE \\
\hline BOND & COVE & DUDE & GATE & JILL & MILE & RACK & SODA & TONE & WINK \\
\hline BRAN & CREW & DUKE & GLAD & JUMP & MOCK & RAGE & SOFA & TOSS & WIRE \\
\hline BREW & CROW & DUST & HAIL & JURY & MORE & RATE & SOLD & TOWN & WISH \\
\hline BULB & CURE & EACH & HAIR & KEEP & MUCK & RIND & SOME & TRAP & WOOD \\
\hline BULK & DAME & EARN & HALL & KICK & NEAR & RISE & SOON & TRAY & WORK \\
\hline BUNK & DARK & EPIC & HALO & KNEE & NICE & RODE & SOOT & TREE & WORN \\
\hline BURN & DART & FACE & HANG & KNOB & NINE & ROOM & STAR & TRIM & WRAP \\
\hline CAGE & DATE & FEET & HARD & KNOW & OBEY & SAID & STAY & TYPE & WREN \\
\hline CAME & DEAL & FEUD & HAWK & LACK & OILY & SAME & SWAP & UGLY & YELL \\
\hline \multicolumn{10}{|c|}{5 Letters } \\
\hline AISLE & BOARD & DONOR & FRAME & LITER & ORDER & QUAKE & SHOWN & STORE & UNION \\
\hline ALGAE & BRUTE & DOUGH & FRESH & MERIT & ORGAN & QUILT & SIEGE & STRAW & UNITE \\
\hline ALIEN & BUILD & DREAM & GAUDY & METAL & PAINT & RABBI & SINCE & STRUT & URBAN \\
\hline ALLEY & BUNCH & EASEL & GEESE & MIMIC & PANIC & RANCH & SKATE & SWAMP & USUAL \\
\hline AMUSE & BUYER & EAVES & GLORY & MINER & PAPER & RAZOR & SKULL & TALLY & VAULT \\
\hline ANGLE & CANAL & ELBOW & GRATE & MONEY & PARTY & RHYME & SLEPT & TENSE & VENOM \\
\hline ANKLE & CAROL & EQUAL & GRIEF & MOTOR & PEACH & RIFLE & SLICE & THING & WAIVE \\
\hline ARGUE & CAUSE & ESSAY & GUESS & MOUSE & PEDAL & RIGHT & SLIDE & THINK & WATCH \\
\hline ARMOR & CHAIR & FABLE & GUEST & MOUTH & PENNY & ROUGH & SLOPE & THREE & WATER \\
\hline AUDIT & CHAOS & FALSE & HAPPY & MUDDY & PHONE & ROUND & SMACK & THUMB & WHEEL \\
\hline AWAIT & CLASP & FAULT & HAVOC & NASTY & PLACE & SANDY & SMELL & TIGER & WHERE \\
\hline
\end{tabular}


Table A1 (continued)

\begin{tabular}{|c|c|c|c|c|c|c|c|c|c|}
\hline BASIC & CLEAN & FIGHT & HONEY & NERVE & PLANE & SAUCE & SPADE & TITLE & WHIFF \\
\hline BASIN & CLOSE & FINAL & HORSE & NEVER & PLANT & SCALE & SPEAK & TOUGH & WHITE \\
\hline BATON & COAST & FIRST & JUICE & NIGHT & PLEAD & SCENE & SPICE & TRACE & WITCH \\
\hline BEGAN & COLOR & FLAME & KNOWN & NOISY & POINT & SENSE & SPRAY & TRADE & WOMAN \\
\hline BELOW & COMES & FLOOD & LAUGH & NOVEL & PORCH & SHEEP & STAIR & TRASH & WORSE \\
\hline BIBLE & CRANK & FLOOR & LEARN & NURSE & POWER & SHEER & STALK & TRIED & WORTH \\
\hline BIRTH & DEATH & FLORA & LEASE & OLDER & PRIME & SHELL & STEAK & TRUCK & WOULD \\
\hline BISON & DECOY & FORCE & LEVER & ONION & PRIOR & SHIRT & STILL & TULIP & WOUND \\
\hline BLUNT & DIRTY & FRAIL & LINKS & OPIUM & QUAIL & SHOCK & STING & TWIST & YOUTH \\
\hline
\end{tabular}

a 4-letter words were not used in Experiments 2 and 4.

Table A2

Nonword Stimuli Used in Experiments 1-3

\begin{tabular}{|c|c|c|c|c|c|c|c|c|c|}
\hline \multicolumn{10}{|c|}{3 Letters } \\
\hline $\mathrm{ACR}$ & CEU & EEF & GWI & MSU & NTI & PPU & TAH & VTA & YAB \\
\hline ADB & CTU & EES & HRA & MYA & NTO & PRA & TBI & VYI & YAE \\
\hline AES & DAS & EEY & HSA & MYG & NUF & PTI & TDO & WAJ & YDA \\
\hline $\mathrm{AET}$ & DBI & EGB & IAR & $\mathrm{NCA}$ & NUS & RBA & TEJ & WFE & YED \\
\hline AGS & DBU & EHU & IET & NDE & NVA & RBO & TEO & WLA & YEK \\
\hline $\mathrm{AMH}$ & DDA & FFO & ILE & NGI & NWI & RDA & TEV & WLO & YGU \\
\hline ANF & DEO & GBA & IMA & NGU & OBJ & REO & TFA & WNE & YHA \\
\hline APL & DFA & GDO & IMR & NHE & ODG & RFU & TGE & WNI & YJO \\
\hline APM & DIK & GEA & JMA & NIB & OEG & RGU & THU & WOB & YLA \\
\hline APN & DLE & GEP & KAE & NIO & OFE & RIF & TIS & WOC & YLF \\
\hline ARF & DMA & GFO & KAR & NKI & OTH & RJA & TMA & WOT & YOB \\
\hline ARH & DMU & GGE & KIS & NMA & OTP & RMU & TNE & WOV & YOT \\
\hline ATB & DNO & GGI & KOA & NNI & OWT & RTA & TPA & WPE & YRA \\
\hline ATO & DOL & GHO & KYS & NNU & PCA & RTE & TPE & WRA & YRC \\
\hline AXL & DRE & GIP & LFE & NPE & PCU & RWA & TPI & XAW & YRD \\
\hline BGI & DRO & GJO & LIO & NPI & PDI & RYA & TPO & XEA & YRE \\
\hline BIR & EAO & GJU & LME & NRU & PEI & RYT & TPU & XOB & YUB \\
\hline BSO & EAP & GLE & LRE & NSI & PHO & SEU & TSV & XOF & YWA \\
\hline BTE & EBW & GLO & MDI & NSO & PLI & SRE & TWE & XSE & ZPS \\
\hline CEI & EDB & GMU & MGE & NTA & PMO & TAE & UTO & XTA & $\mathrm{ZPT}$ \\
\hline \multicolumn{10}{|c|}{4 Letters $^{a}$} \\
\hline $\mathrm{ABDL}$ & DERO & FASO & KDIS & LIOT & MTHE & NWEI & RHAI & STEA & TSRA \\
\hline ACTR & DFUE & FECA & KLTA & LJLI & NAEC & NWSO & RIWE & STOS & UDED \\
\hline AEAR & DHEI & FHEC & KLUC & LKBU & NBAR & OMOR & RMIT & TAED & UTCD \\
\hline ASME & DHRA & FHSI & KNIW & LLBA & NBKU & PDIR & RNBU & TAEP & VOEC \\
\hline BAML & DILW & FLOO & КPEC & LLGA & NCOE & PEHL & RNEW & TAPR & WATI \\
\hline BBAE & DKEU & GELA & KSEE & LLIH & NCOI & PJUM & RODP & TARD & WBRE \\
\hline BEIT & DLAC & GERA & KWOR & LLLU & NDSE & PKEE & ROWC & TDSU & WHEC \\
\hline BEOY & DLSI & GNIA & LADE & LLYE & NEIV & PLIL & RPWA & TEAG & WNOK \\
\hline BKON & DMEA & HESO & LADG & LNAC & NEKE & PMAC & RSIE & TELB & WRAE \\
\hline BLBU & DMOO & HKWA & LALH & LODF & NEVI & PTAR & RTEE & TEMA & WSAP \\
\hline CDSU & DNEO & HLED & LBAE & LPIS & NGHA & RAEB & RUHO & TFED & XAIT \\
\hline CEHA & DOLH & HLIA & LCEU & LTTI & NIEC & RAUA & RWEE & TFEE & YLOI \\
\hline CGEA & DONP & HPTA & LCLE & LVEI & NITH & RCEW & SCDI & TMEE & YPET \\
\hline CIKP & DOWO & HSWI & LDOB & LYUG & NNIE & REAN & SERU & TOLO & YRAF \\
\hline CIPE & DPEE & HWMO & LDSO & MCEA & NOET & REAW & SHGA & TOOS & YRUJ \\
\hline COKL & DRAK & IRNO & LEIM & MCKU & NOWT & RECU & SIIR & TPUT & YSTA \\
\hline CRAK & DSIA & KAET & LFMI & MEBA & NRDI & REEM & SITF & TREA & YTRA \\
\hline DASO & DTEI & KCIK & LFUO & MPOE & NREA & REHO & SLSE & TSCE & YVRA \\
\hline DBNO & DUTH & KCLA & LHOA & MSEO & NROW & RETI & SODE & TSLA & ZEAH \\
\hline DERA & ERMO & КСMO & LIMS & MTAE & NUKP & REYP & SONO & TSOC & ZIES \\
\hline
\end{tabular}


Table A2 (continued)

\begin{tabular}{|c|c|c|c|c|c|c|c|c|c|}
\hline \multicolumn{10}{|c|}{5 Letters } \\
\hline AEESV & CPLEA & GESTU & KNACR & LOSEP & NAYDS & OOMRT & RLTIE & SRTIA & UKRTC \\
\hline AETCR & CSELA & GETRI & KRTUC & LRFAI & NCELA & ORWPE & ROALF & STCOA & UQALE \\
\hline AICBS & CSENE & GIRTH & KSEAP & LRIEF & NDOUW & OTHUY & ROFLO & SYION & USNER \\
\hline AITAW & CWHTI & GNHTI & KWEAU & LSEIM & NEESS & PCEIS & ROPRI & TAKSL & VENER \\
\hline AKSTE & DHUGO & GTHFI & LAEGN & LSPAC & NEIAL & PEALD & RPAEP & TAPIN & VNERE \\
\hline ALNAC & DRORE & GURAE & LAYTL & LTNBU & NESET & PEONH & RTEAW & TBERU & $\mathrm{VOACH}$ \\
\hline AOCSH & DRTEI & HCPEA & LCOAR & LTUQI & NHCBU & PPYAH & RTEHE & TDERA & VRLEE \\
\hline APLTN & DTUIA & HEDAT & LDUWO & LUAIQ & NHYOE & PTULI & RUTTS & TLEPS & VWEAI \\
\hline ASEDP & DYDUM & HESRF & LEAES & LUUAS & NIFLA & QAELU & RYOGL & TMEIR & WBEOL \\
\hline ASKMC & EPDLA & HGUAL & LEHEW & LVEON & NINOO & RANLE & SBION & TOWHR & WETHI \\
\hline ASTWR & EPMIR & HITGN & LESID & LYELA & NLSIK & RAODB & SCEOM & TPOIN & WIFFH \\
\hline BIARB & ERYHM & HITRB & LFEAM & MAWON & NNOWK & RAROM & SEEGI & TRESO & WMAPS \\
\hline BLIEB & ESALE & HNTKI & LFODO & MEADR & NOAGR & RAYTP & SELAF & TRSHI & WOBLE \\
\hline CAESU & EUCAS & HOSNW & LFUTA & MEALT & NOIUN & RCOOL & SERHO & TSFIR & YASRP \\
\hline CHIRA & FALEB & HPESE & LHLES & MEONV & NSECI & RDOON & SESUG & TSNGI & YBERU \\
\hline CHPRO & FEMRA & HUTOM & LISEC & MIPUO & NSIBA & RDYIT & SEYAS & TTELI & YCODE \\
\hline CMIIM & FIGRE & HWACT & LIUDB & MRENI & NSUER & REEWH & SLEIA & TTWIS & YOMEN \\
\hline CNAIP & GABEN & KAEST & LLSTI & MSAEU & NTOAB & REFCO & SNYAT & TUENI & YPNEN \\
\hline CNHRA & GELAA & KCHSO & LNEPA & MUTBH & OESUM & RETGA & SREHE & UETBR & YUGDA \\
\hline COESL & GESEE & KEALN & LODRE & NAURB & OGUHR & RHTAS & SREWO & UGOHT & ZARRO \\
\hline
\end{tabular}

a 4-letter nonwords were not used in Experiment 2.

Received February 6, 2013

Revision received June 18, 2013

Accepted June 20, 2013 